\title{
Instrucción Progresiva \\ INHERENTE A LA PRÁCTICA \\ ESTANDARIZADA DE LA FORMA \\ UTILIZANDO EL IAIDO \\ COMO EJEMPLO
}

POR KIM TAYLOR
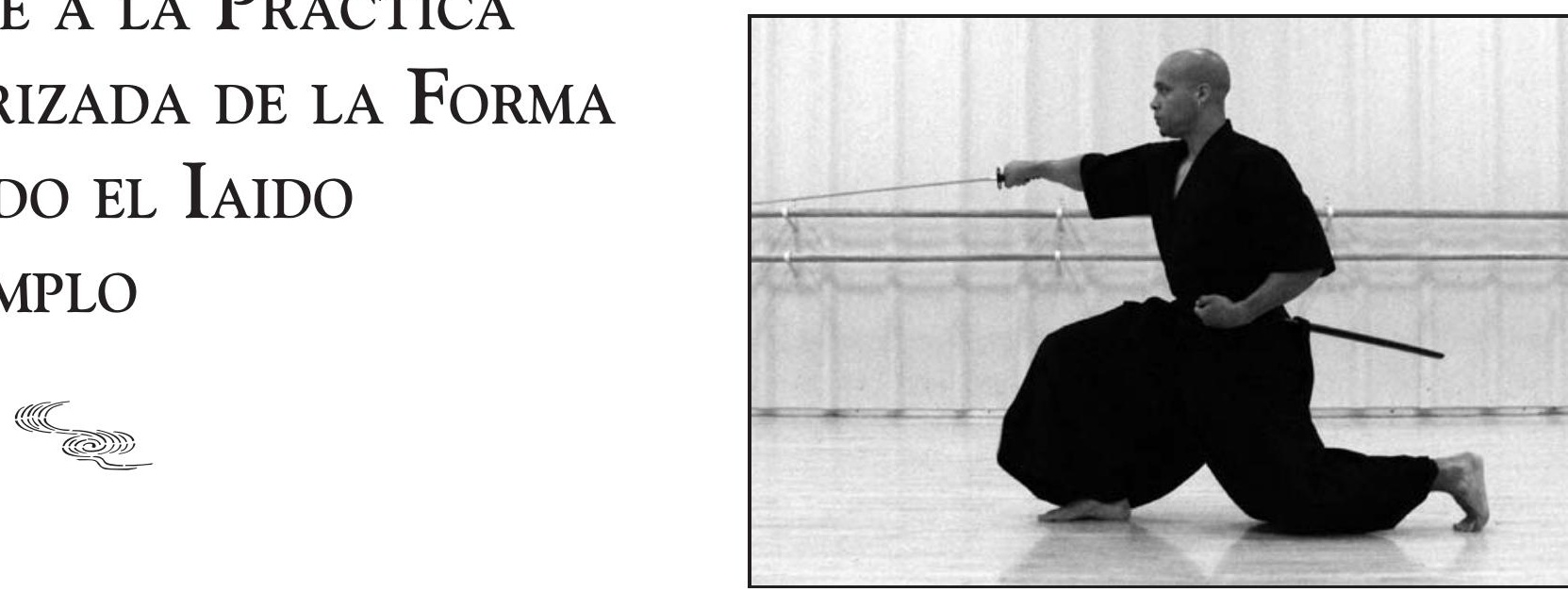

\section{Resumen}

La práctica de las katas, o movimientos diseñados y predeterminados en las artes marciales, permite al estudiante aprender movimientos básicos específicos y comprender su significado. Muchas artes marciales basadas en las katas organizan su currículum en series de ejercicios. Utilizando el iaido (desenvainado de la espada) como ejemplo, este trabajo muestra cómo una serie de ejercicios puede progresar, kata tras kata, de ideas simples a más complejas, y proporcionar un conocimiento más profundo del conjunto de las series.

\section{Introducción}

La instrucción a través del entrenamiento de la kata ha sido una parte importante del entrenamiento en muchos sistemas marciales japoneses clásicos y modernos. El entrenamiento de la kata ha sido a veces criticado, especialmente por artistas marciales occidentales contemporáneos como demasiado formal, rígido y carente de realismo. Pero su utilización durante siglos sugiere que, mientras no sea la única forma de entrenamiento, la práctica de la kata tiene importantes aspectos que dar a conocer.

Este artículo explora las formas en las que la práctica de una kata específica, la Omori-ryu de la Muso Jikiden Eishin-ryu, puede ayudar en el desarrollo de importantes habilidades básicas. Mantiene que este régimen de entrenamiento puede ayudar significativamente a los artistas marciales a desarrollar una base sólida en términos de postura correcta y de generación de potencia a través de las caderas. El autor apunta que considera que el iaido (el arte de desenvainar y cortar en un solo movimiento con la espada) es uno de los mejores medios para que un estudiante de artes marciales se concentre en aspectos tales como la postura, el control de la cadera y la transferencia de la potencia. Esto se debe a que el iaido puede considerarse un arte "cerrado", que se realiza a través de una práctica diseñada para guiar al estudiante a la repetición de una forma ideal. Esto contrasta con un arte "abierto" en el que se incluyan muchas más variaciones en la ejecución debido a la presencia de otra persona. Unos buenos ejemplos de deportes occidentales cerrados y abiertos podrían ser la gimnasia y el tenis respectivamente. Indudablemente, las formas modernas de competición de las artes marciales exhiben también muchas características "abiertas". En el manejo japonés de la espada, el iaido ha mantenido una estructura "cerrada", mientras que el kendo es un ejemplo de una forma "abierta" debido a su énfasis en la competición (shiai). 
Un segundo objetivo de este artículo es hacer explícito lo que a menudo es implícito en el entrenamiento de la kata. En los sistemas tradicionales, a los estudiantes no se les suele decir lo que están aprendiendo en cada kata. Existe una suposición de que la habilidad se desarrollará naturalmente mediante la práctica, y que este "entendimiento en desarrollo" infundirá todos los elementos del entrenamiento a lo largo del tiempo. Esta es una función de los modelos culturales que acentúa la jerarquía y el aprendizaje por repetición, existiendo poca discusión acerca del método y del propósito. Mientras que existen muchos aspectos por los que puede ser recomendado el entrenamiento tradicional, un examen más detallado de los elementos efectivos presentes en la instrucción en artes marciales puede ayudar a mejorar dicha instrucción.

\section{Lecciones de la Omori-ryu de la Muso Jikiden Eishin-ryu}

El propósito de este artículo es ofrecer una idea del tipo de instrucción progresiva que uno puede recibir a través de la práctica de un conjunto de katas (movimientos diseñados y predeterminados). Estas lecciones suelen estar profundamente arraigadas en el proceso de práctica, y a veces son difíciles de agradecer. Además, el enfoque tradicional en el aprendizaje de la kata -imitación en vez de discusión- también puede servir en ocasiones para entorpecer su ejecución. El entrenamiento de la kata en muchas formas de artes marciales incluye características similares; esto es, estandarización de la técnica, énfasis en la forma, secuencia y tiempo correctos, y un acento en el aprendizaje mediante la experiencia frente al aprendizaje teórico.

En este caso utilizaremos una kata de iaido como ejemplo específico. Discutiremos la forma Omori-ryu de la Muso Jikiden Eishin-ryu, una escuela bastante famosa del desenvainado de la espada que fue fundada hace varios siglos y organizada en su forma actual por Oe Masamichi (1852-1927) a principios del s. XX. La Omori-ryu es la primera serie de katas que se enseña en la Muso Jikiden Eishin-ryu, y por ello está pensada para demostrar los fundamentos de la práctica.

La primera kata que aprenderá un estudiante en la Omori-ryu es Mae (moviéndose al frente), que es bastante simple y consiste en un corte horizontal y luego vertical. Mae es la base, la raíz, la kata original para esta secuencia y para un ojo entrenado su realización revelará la profundidad del conocimiento del ejecutante.

Siguen diez katas más, muchas de las cuales están estructuradas más o menos bajo el mismo patrón de un corte horizontal y luego vertical. Existe, sin embargo, una secuencia de desarrollo para la progresión: en cada una se repiten algunos principios básicos del movimiento a la vez que también se añade alguna novedad. Se espera que el estudiante aprenda la nueva información y luego la aplique en Mae la próxima vez que realice la kata.

$\mathrm{Al}$ igual que muchas habilidades físicas altamente complejas que implican una integración física y mental, hay muchas cosas que se aprenden y se enseñan en la kata. Por ahora podemos concentrarnos en algunos aspectos para la explicación. El foco principal de esta discusión estará en la utilización de las caderas para proporcionar potencia desde el suelo a la parte atacante de la espada. Indudablemente mencionaremos otros aspectos más específicos del iaido, pero la postura y la utilización de las caderas son clave en todas las artes marciales japonesas, de modo que esto proporcionará una visión en el proceso de aprendizaje de las katas que podrá ser entendida por un público más amplio.

Aunque debería ser absolutamente obvio lo que voy a decir, lo que sigue es mi entendimiento particular del iaido, y mi entendimiento particular de los principios fundamentales. No se pretende que éste sea definitivo, ya que otros instructores o estudiantes pueden tener diferentes puntos de vista.

\section{ACLARACIÓN}

Con las primeras cuatro katas descritas a continuación, fijaremos una buena postura y una gran estabilidad en las caderas, a la vez que también aprendemos cómo proyectarnos directamente hacia el objetivo desde cualquier ángulo de partida

\section{GuÍA: \\ Once katas \\ de la Omori-ryu \\ utilizadas para demostrar la instrucción progresiva}

I Mae: frente

2 Migi: derecha

3 Hidari: izquierda

4 Ushiro: atrás

5 Yae gaki: defensa doble

6 Uke nagashi: recibir/

desviar

7 Kaeshaku: ayudante

8 Tsuke komi: distancia corta

9 Tsuke kage: sombra de la luna

10 Oi kaze: persiguiendo el viento

II Nuki uchi: corte desenvainando 
En primer lugar, una rápida descripción de la kata.

Este es un corte horizontal al frente, seguido de un corte final vertical, chiburi (sacudiendo la sangre) y noto (meter la hoja en la funda). Las fotografías deberían ofrecer una idea clara de los movimientos.

El movimiento de esta primera kata es en línea recta hacia delante. Tenemos que encontrar cómo dirigir la potencia desde las caderas directamente hacia delante y al oponente como primer principio. Para hacerlo, acentuamos el movimiento desde el centro del cuerpo, el centro de equilibrio en el tanden, que es un punto aproximadamente a dos dedos por debajo del ombligo y en la línea media del cuerpo. Puedes localizar el lugar tumbándote sobre una barandilla hasta llegar al punto donde puedas balancearte en cualquier dirección (brazos y piernas en lados opuestos, brazo y pierna uno a un lado, y sentado erguido con tus piernas en cada lado seguramente te darán una idea bastante buena).

Un buen ejercicio para descubrir cómo moverse desde el tanden y que músculos participan es utilizar un jo (un palo de 4 pies) con un compañero. El compañero se coloca enfrente y ofrece resistencia a tu tanden a través del palo, mientras te elevas y avanzas.

\section{Desenvainar \& Cortar}

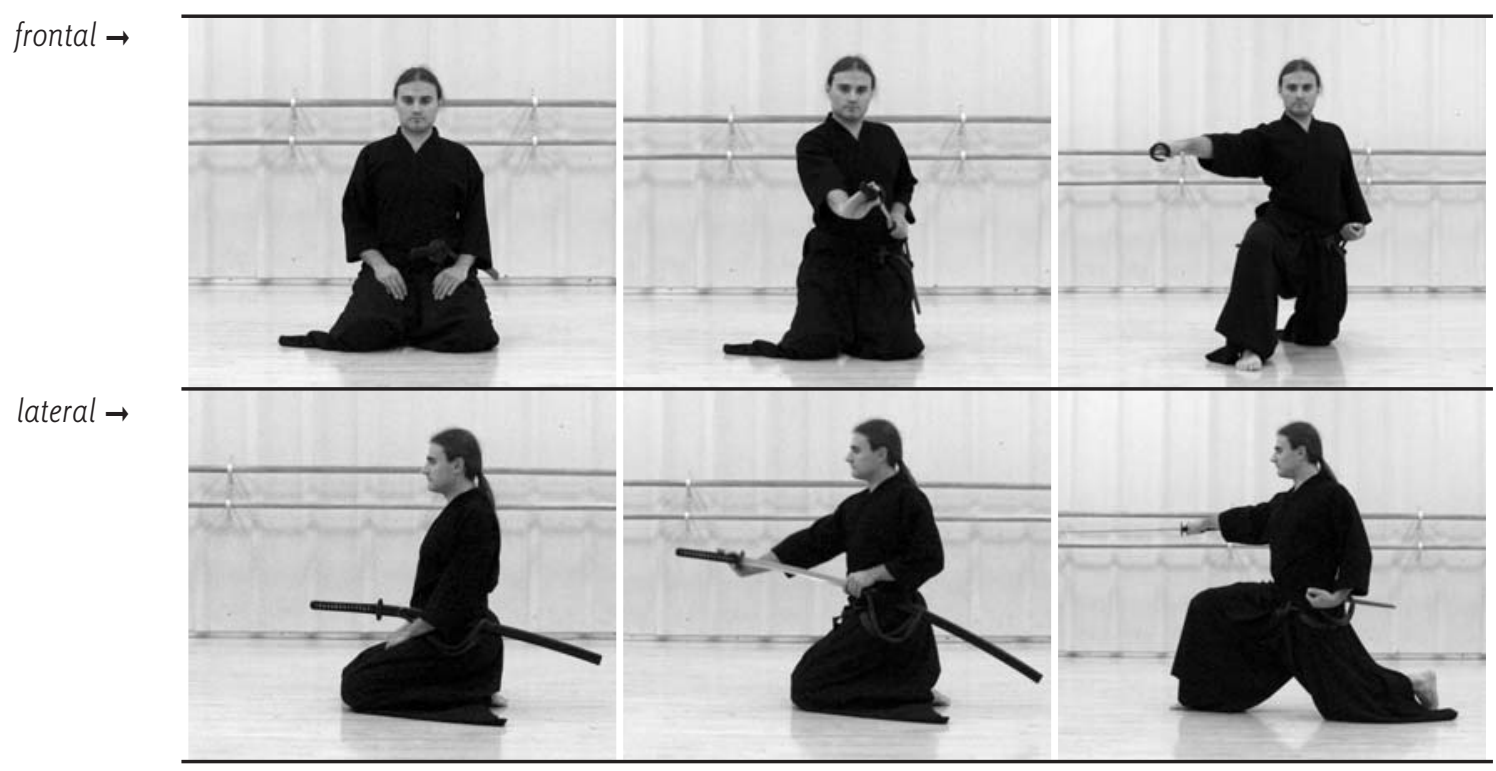

Este movimiento tiene que partir desde el centro, por lo que las manos están colocadas de tal manera que se mueven desde el centro hacia dentro y hacia delante con el desenvainado. Cuando se agarra la empuñadura, ambas manos van juntas hacia arriba, la mano izquierda alcanza primero la empuñadura, y luego la derecha. Agarra la empuñadura desde abajo, no en la parte superior, lo que mantiene los codos flexionados, cercanos al tanden.

El corte tiene que tener potencia desde las caderas. Las caderas no se elevan y luego bajan durante el movimiento, sino que suben la altura correcta y se dirigen hacia delante durante el corte. El corte y el apoyo del pie están sincronizados en el tiempo y el movimiento nivelado de las caderas evita que se produzca un movimiento ondulante de la punta en el corte.

Al final del corte, los nudillos deberían estar justo por debajo del nivel del hombro derecho. La punta debería estar justo por debajo, paralela al suelo. Se da potencia al corte horizontal unificando la punta con las caderas mediante los hombros y el torso. Esto se hace manteniendo los hombros abajo, axilas firmes, y cerrando la escápula en la parte inferior, a la vez que se abre el pecho. 


\section{Golpe vertical}

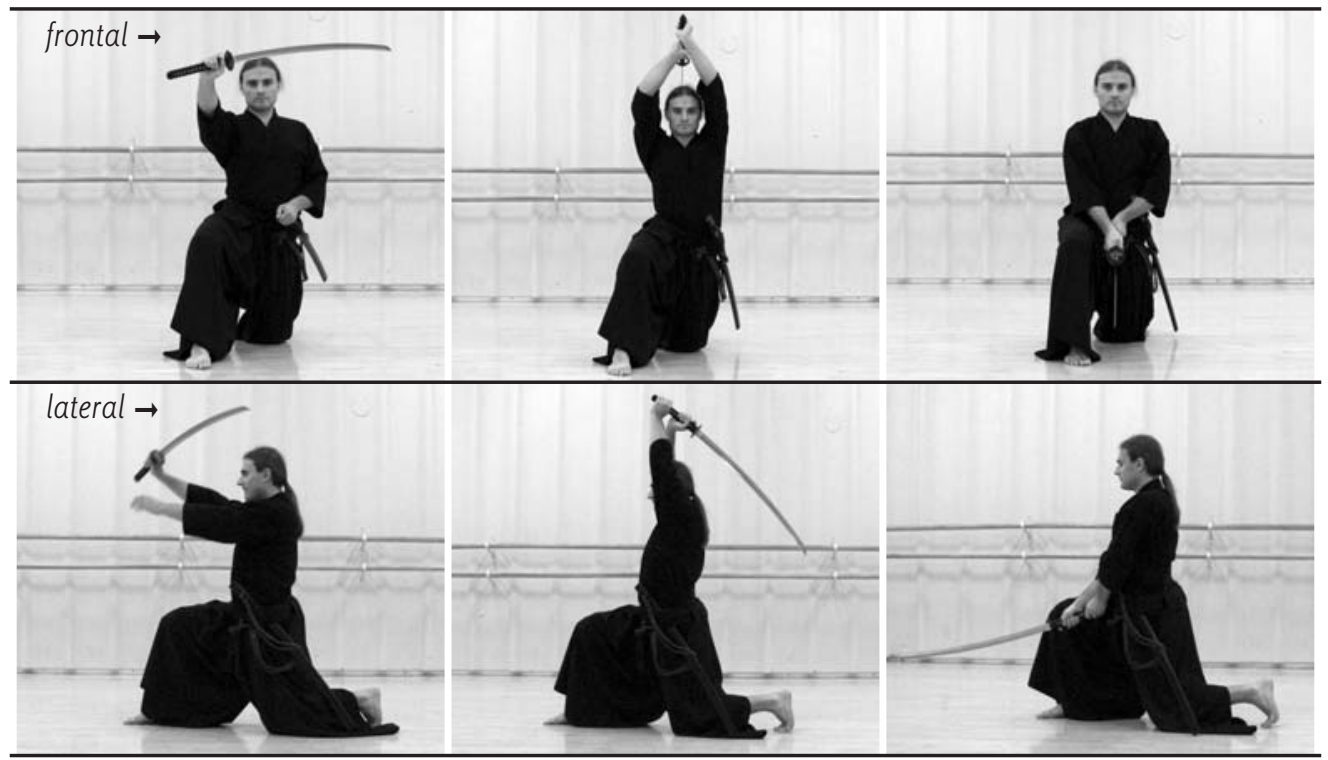

En el siguiente movimiento, los hombros y brazos han de estar relajados, mientras las caderas contienen su potencia. La hoja se mueve alrededor y arriba mientras la mano izquierda se mueve desde el centro del cuerpo directamente hacia arriba para agarrar la empuñadura. La punta se saca y eleva al mismo tiempo que las caderas son conducidas hacia delante y se estabiliza el corte con los meñiques, axilas y estómago a lo largo de la parte del arco donde se realizaría el corte.

Mantener las caderas bajo los hombros y mantener una postura erguida es muy importante para lograr la habilidad de dejar caer el peso en el borde cortante de la espada. Cuanto más cerca esté tu tanden de estar bajo el corte, tanto mayor peso se puede dejar caer sobre él. Piensa en una escalera con ganchos en la parte superior, si la inclinas contra una pared no estás ejerciendo demasiada presión hacia abajo, pero si la enganchas por encima de la parte superior de la pared para que la escalera esté vertical, consigues la máxima presión. La espada es el gancho, y tu cuerpo es la escalera. El corte es la pared.

\section{Sacudiendo la sangre}

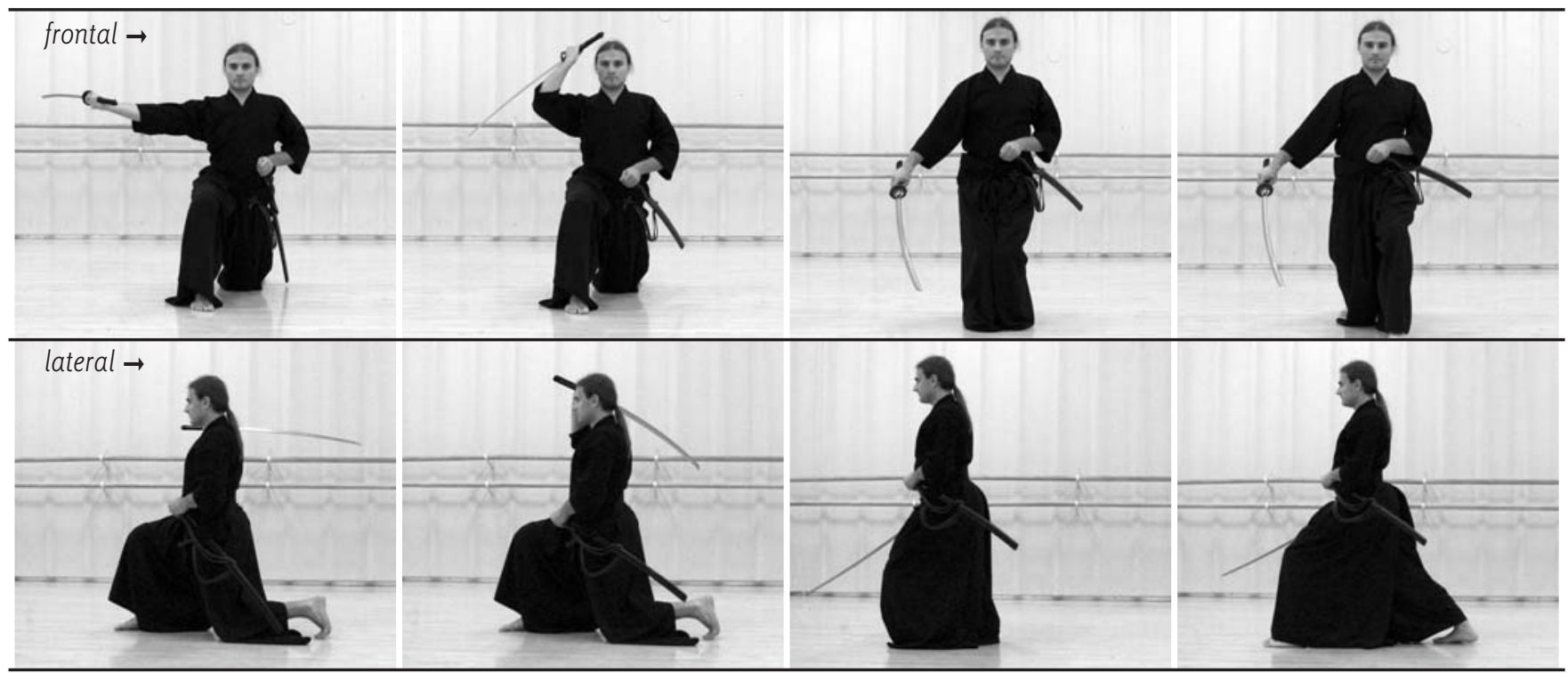

Revista de Artes Marciales Asiáticas $\diamond$ Volumen 4 Número 2 (74-95) - 2009 
Enfundando
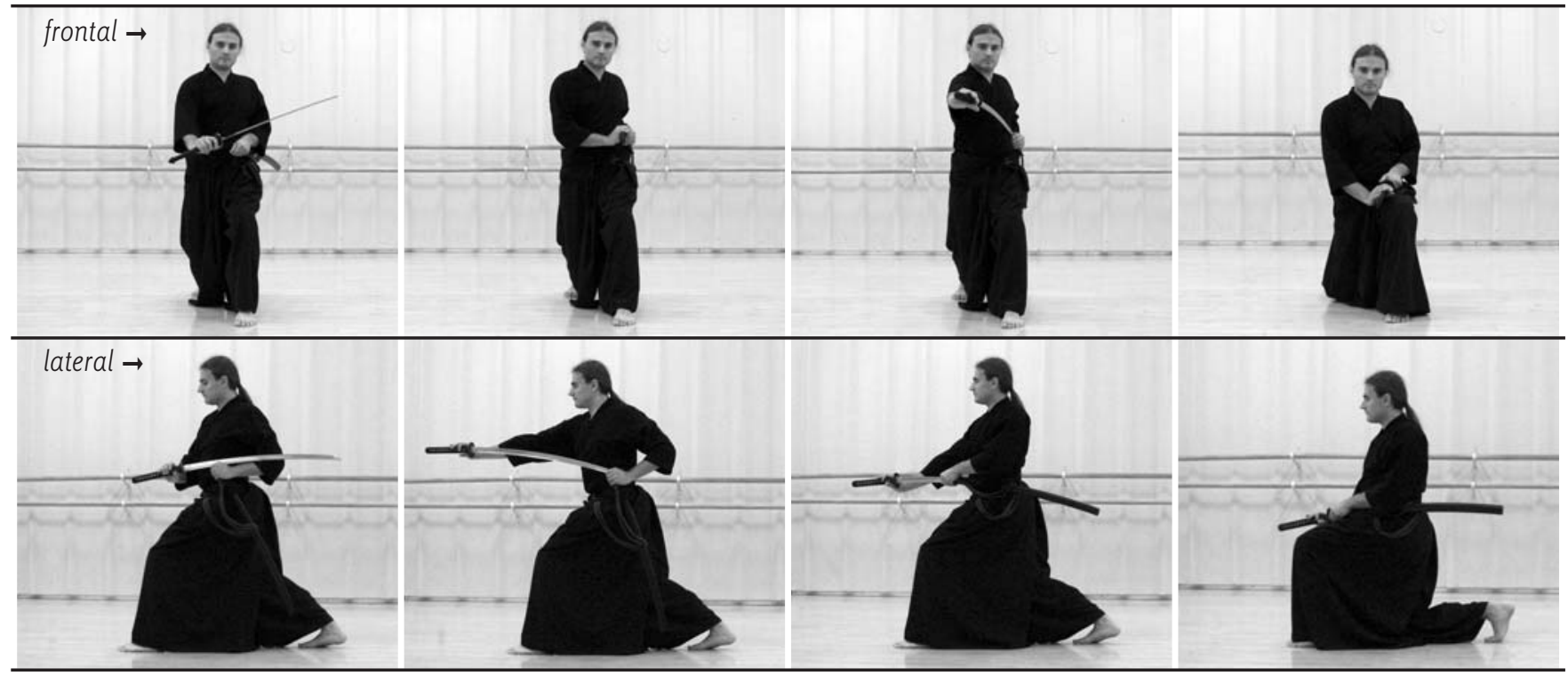

Lecciones aprendidas: En esta kata hemos encontrado nuestro tanden, hemos aprendido cómo movernos desde él, y cómo unir el trío punta de la espada - caderas - suelo. Sobre la teoría de que no podemos aprender todo de una vez, dejaremos ahora Mae y avanzaremos a la siguiente kata para que podamos aprender algo nuevo.

\section{\#2 - Migi}

Desenvainar $\&$ corte a la derecha

\section{DEFENDIENDO A LA DERECHA}

El oponente está sentado a tu izquierda. Comienza a levantarse y desenvaina. Giras $90^{\circ}$ a la izquierda y cortas horizontalmente cruzando su pecho, elevas la hoja como en \#1 Mae, y cortas hacia abajo desde su cabeza hasta su ingle. El chiburi, cambio de pie y el enfundado son como en Mae, pero el pie contrario está adelantado durante todo el movimiento.

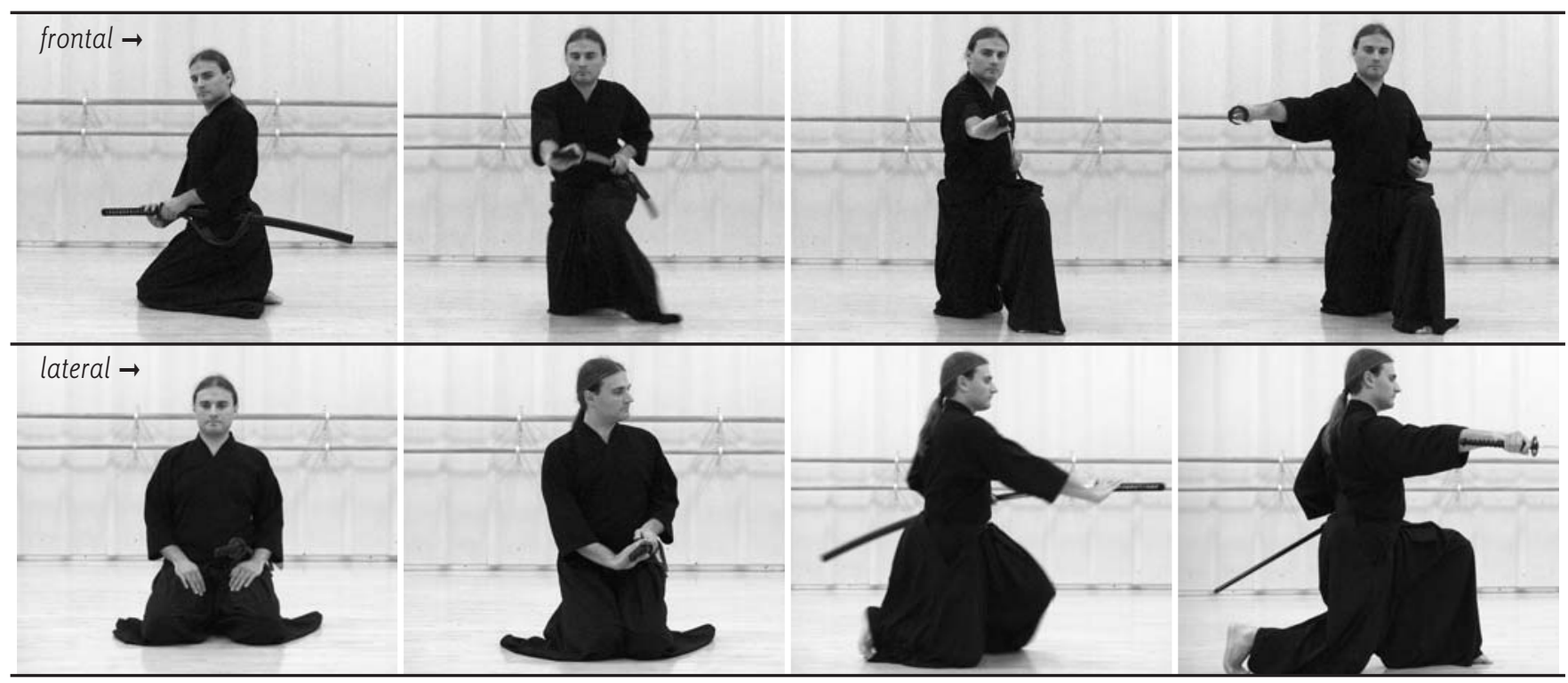

Esta técnica es hacia delante (Mae), y se realiza sólo hacia un oponente que está a la izquierda. Podemos conseguir el mismo movimiento directo hacia el oponente que hacemos en Mae, pero mientras giramos. Para hacer esto, tenemos que imaginar una línea recta que va desde nuestra mano derecha, a través de la empuñadura, al centro del oponente. Nuestra mano derecha se mueve a lo largo de esta línea cuando atacamos. Para elevarse y girar al mismo tiempo, necesitamos realizar algunos movimientos de cadera bastante complejos y cambios de peso. 
Primero mueve la rodilla derecha hacia el oponente, para tocar la rodilla izquierda. Esto asegura que en realidad no nos movemos hacia atrás cuando giramos, y también coloca nuestra rodilla derecha en el centro de nuestro cuerpo cuando estamos sentados. Ahora, tan pronto como comencemos a elevar las caderas, en línea recta hacia delante desde nuestra posición original, nuestro peso cambia a la rodilla derecha. Yendo hacia atrás hacia la cadera izquierda, y yendo luego a la cadera derecha, nuestro cuerpo gira de forma natural a la izquierda. Al mismo tiempo comenzamos a sentir la potencia moviéndose desde el tanden hacia el oponente mientras desenvainamos la hoja a lo largo de esa línea recta. El pie de atrás se apoya por completo para parar el giro mientras cortamos horizontalmente.

Nada de esto funciona si lanzamos nuestra cabeza hacia delante para girar. Si eso ocurre, giraremos hacia fuera y estaremos desequilibrados, ya que nuestra cabeza actúa como un peso excéntrico en el lado de un eje giratorio. Así como no giramos la cabeza a la derecha o a la izquierda cuando caminamos, o no nos levantamos lanzando primero nuestra cabeza y pecho, tampoco nos inclinamos hacia delante para defendernos a la derecha (\#2 Migi).

Lecciones aprendidas: Con la segunda kata hemos aprendido más cambios de caderas y peso, reforzando el sentimiento de atacar directamente al centro del oponente, y llegando a ser mucho más conscientes de nuestra cadera derecha cuando la dirigimos alrededor y adelante. También hemos aprendido cómo cortar con las piernas cambiadas, lo que significa que estamos enraizados en el suelo de forma diferente, lo que nos ayuda a comprender mejor lo que está pasando en las caderas.

Reflexión: Lo que retomamos en \#1 Mae: ahora tenemos un mejor conocimiento de nuestra cadera derecha (ya que la mano derecha la roza y la imaginamos dirigiéndose hacia el oponente), sabemos que no hay que lanzar nuestra cabeza hacia delante cuando nos elevamos para defendernos al frente (Mae) (al igual que no podemos hacerlo cuando nos defendemos a la derecha, \#2 Migi), y probablemente realizaremos un tirón más enérgico de la funda puesto que tenemos que utilizar más nuestra mano izquierda para sacar la punta de la hoja fuera de la funda.

\section{DEFENDIENDO A LA IZQUIERDA}

\#3 - Hidari

Esta kata gira para encarar a un oponente al lado derecho.

Desenvainar $\&$ corte a la izquierda
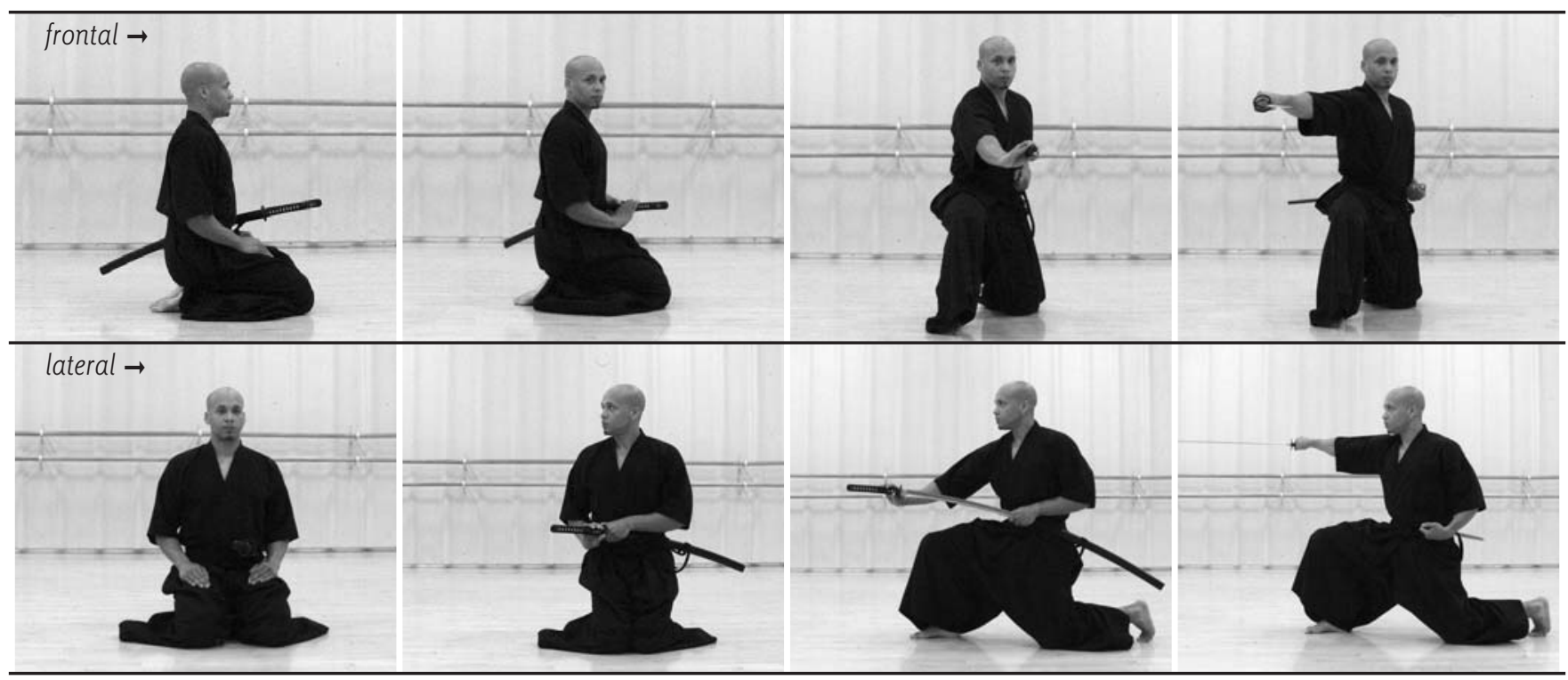

Aquí hay una forma ligeramente diferente de visualizar nuestro giro, ya que una línea recta desde la mano derecha al oponente dejaría la espada atrás. Necesitamos mover la rodilla izquierda a la derecha, elevarnos y girar mucho más parecido a como hicimos atacando a la derecha (Migi), cambiando el peso a la rodilla izquierda y retirando la cadera derecha. En este caso, sin embargo, los movimientos de la mano izquierda pasan nuestra línea central y cogen la empuñadura, moviéndola a la mano derecha en su camino directo hacia el objetivo. 
Mientras alcanzamos la posición donde golpeamos al objetivo, las caderas están girando más allá de ese objetivo, o no estarán haciendo nada. Aquí necesitamos girar las caderas para estar en ángulo recto, y luego retrasar la cadera izquierda hacia el pie izquierdo para enraizarlo cuando cortamos horizontalmente. Esta es la primera vez que hemos tenido que cambiar la rotación de las caderas para estabilizarlas previamente al corte. También es la primera vez que hemos cambiado el movimiento de la espada de la mano izquierda a la derecha y otra vez a la izquierda en el corte vertical.

Lecciones aprendidas: Atacando a la derecha y a la izquierda (\#2 Migi y \#3 Hidari) estamos empezando a conseguir una mejor sensación de conducción de la empuñadura hacia el oponente, a la vez que mantenemos la cadera fuerte y la postura erguida. También hemos desarrollado una sensación en ambas partes de la cadera, y cómo pueden utilizarse en combinación con el tanden para crear una base sólida para los cortes. Se ha demostrado la importancia del pie atrasado para el corte, y la suave y más eficiente transferencia de potencia de una mano a otra.

Reflexión: La posición del pie y la estabilidad de las caderas deberían estar mucho mejor ahora cuando se defiende al frente (\#1 Mae).

\section{\#4- Ushiro}

\section{Desenvainar y corte} hacia atrás

\section{DEFENDIENDO HACIA ATRÁS}

El oponente está sentado a tu espalda. Comienza a levantarse y desenvainar. En un movimiento suave, giras $180^{\circ}$ a la izquierda y cortas horizontalmente a través de su pecho, levantando la hoja como en \#1 Mae (frontal), y cortas hacia abajo desde su cabeza hasta su ingle. El chiburi, cambio de pie y enfundado son iguales que en Mae, pero el pie contrario está adelantado durante todo el movimiento.

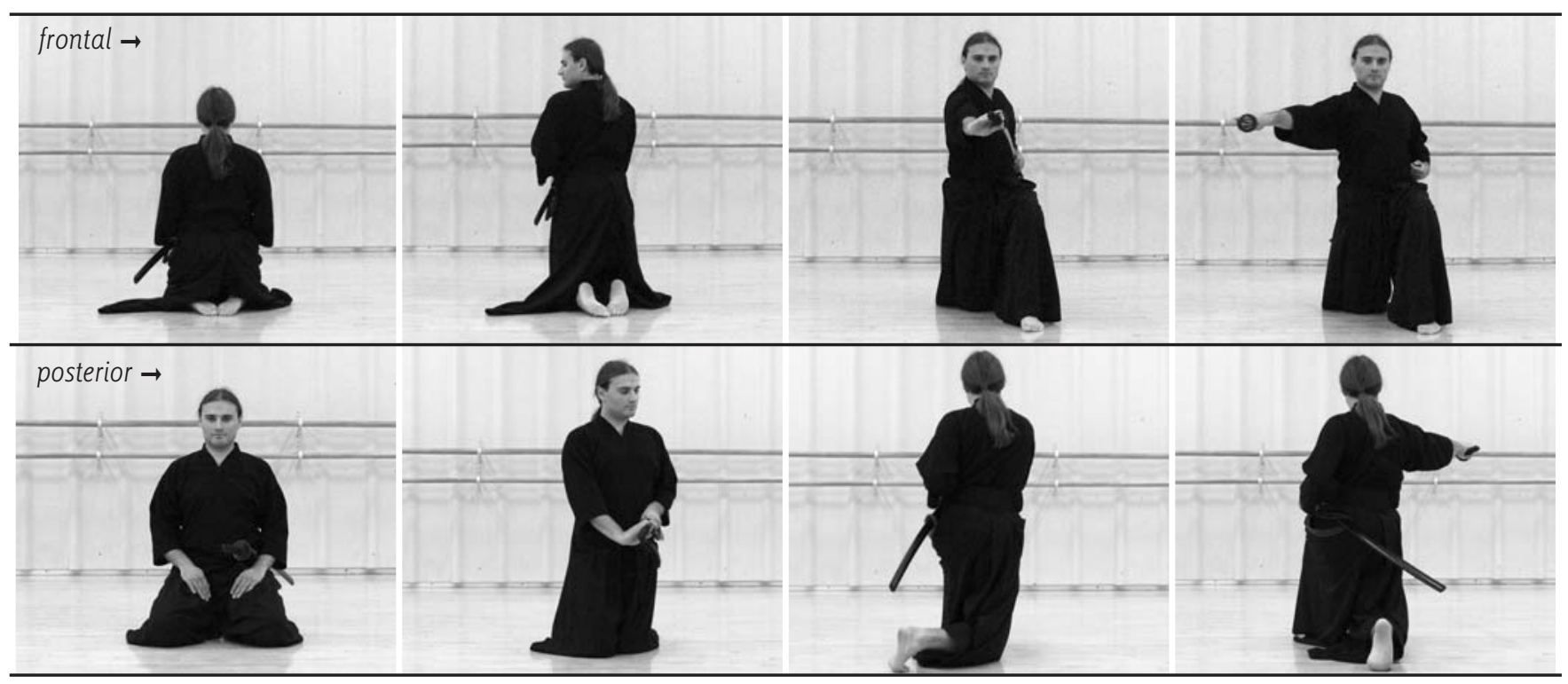

Esta kata, Mae hacia atrás, es un refuerzo excelente de las habilidades que hemos aprendido hasta ahora en el giro, ya que giras $180^{\circ}$, y cualquier inclinación de la cabeza o del torso te desequilibrará. La rodilla derecha cambiando hacia la izquierda y frente a la rodilla izquierda te permitirá cambiar tu peso como hiciste en defendiendo a la derecha y la izquierda (Migi y Hidari), para que puedas girar.

El nuevo problema aquí es que tus manos no pueden "ver" al oponente, por lo que es difícil desenvainar en línea recta hacia él. Tendrías que desenvainar a través de tu propio cuerpo, así que tenemos que ocuparnos del giro. Para desenvainar en línea recta hacia el objetivo, tenemos que saber que nuestra mano ha pasado sin rozar la cadera izquierda. Aquí es cuando la mirada adquiere importancia. Sin forzar el cuello, giramos nuestros ojos, y luego nuestra cabeza mientras nos elevamos hasta que podemos ver el objetivo y están en 
posición para cortar directamente. En realidad la mano derecha se está alejando ligeramente del oponente, por lo que cuando nos alineamos para desenvainar hacia él tenemos que cambiar de un movimiento de la mano derecha a un movimiento muy fuerte de la mano izquierda para dejar libre la funda de la hoja mientras giramos. Superar este giro requiere una gran atención a nuestra postura y a mantener las caderas trabajando sin poner tensión en la parte superior del cuerpo y especialmente en los hombros.

Lecciones aprendidas: Ahora hemos aprendido cómo ocuparnos de nuestra falta de visión de la mano derecha, y ante un oponente que en principio no podemos ver hemos aprendido la importancia de llegar a verlo utilizando ese movimiento para comenzar nuestro giro y el propio corte.

\section{ACLARACIÓN}

La siguiente kata requiere del ejecutante que aprenda a seguir los principios de las primeras cuatro katas y adquiera mayor movilidad, con una segunda progresión de ataque y defensa.

\section{Reflexión:}

Ahora podemos defendernos al frente (Mae) con una buena postura, gran estabilidad en las caderas, contra un oponente situado en cualquier posición a nuestro alrededor.

\section{DEFENSA DE “DOBLE ESGRIMA”}

El oponente está sentado en la defensa frontal (Mae). Cuando empieza a levantarse, desenvainas y cortas como en Mae, pero sale hacia atrás fuera del alcance. Das un paso hacia delante con el pie izquierdo mientras cortas hacia abajo desde su cabeza a su ingle. Ejecuta la "defensa de doble esgrima" y enfundado, retirando el pie izquierdo a la rodilla derecha. En este punto, el atacante golpea a tu rodilla derecha por lo que desenvainas y bloqueas este ataque mientras das un paso hacia atrás con el pie izquierdo. Lleva la rodilla izquierda hacia el pie derecho, conduce la hoja alrededor y sobre tu cabeza, y corta hacia abajo casi hasta el suelo mientras cambias tu pie derecho adelante otra vez a la posición en ángulo recto. Levanta la punta por fuera del oponente, y luego realiza chiburi y enfundado como en \#1 Mae.

Esto es Mae con un segundo asalto. La característica principal de esta kata está en el segundo ataque y defensa, demostrando la importancia de una "alerta relajada" (zanshin), y que la kata nunca está realmente "terminada" hasta su completo final. También aquí hay nuevas lecciones relativas a la postura.

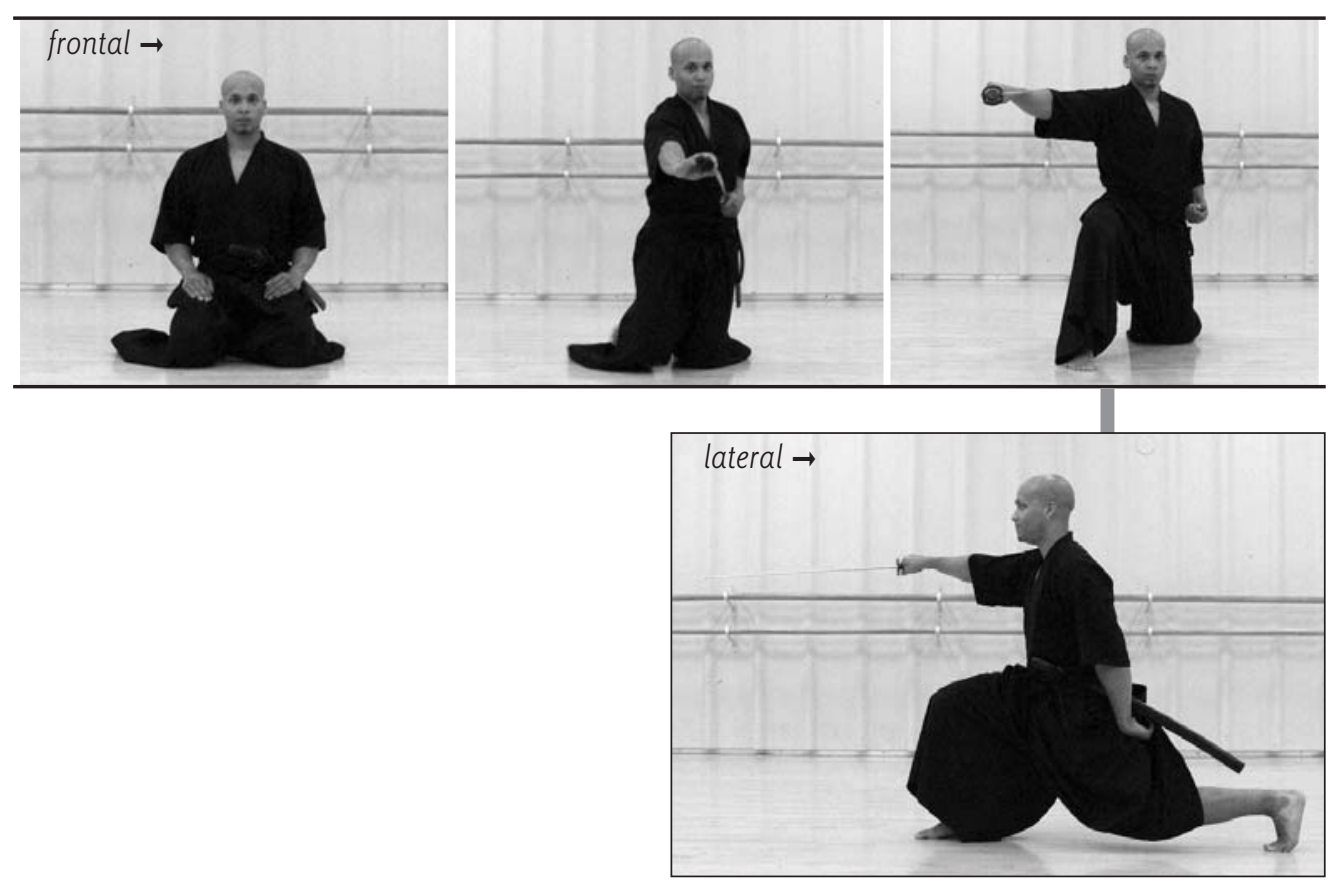

Desenvainar \& Cortar $\# 1$ 
En el primer corte horizontal, el oponente se ha doblado hacia atrás para evitar ser cortado, por lo que tienes que perseguirle. Haces esto dando un paso hacia delante con el pie izquierdo y cortando mientras te flexionas sobre la rodilla.

La parte clave de la instrucción en esta kata esta aquí, cuando colocas el pie izquierdo en el primer corte. Para moverte hacia delante suavemente quitarás el peso de la rodilla izquierda, para que el movimiento sea ahora suave y con un arco natural de las caderas.

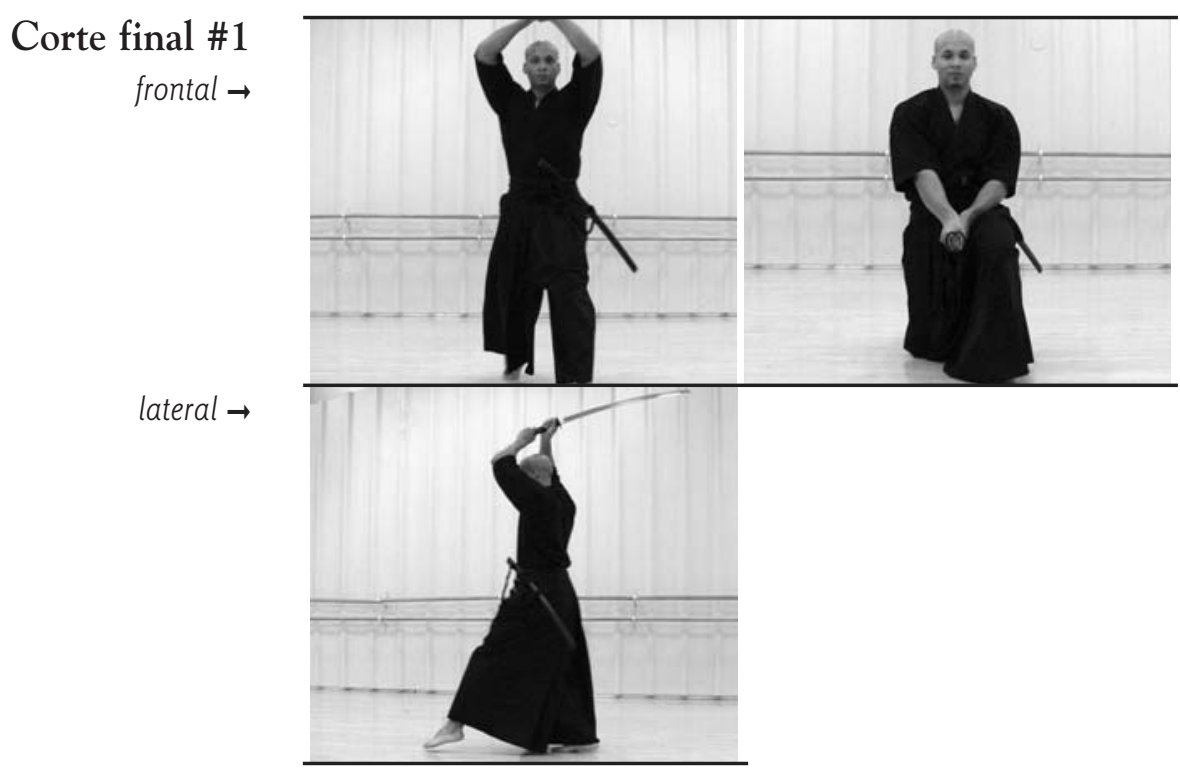

No golpees tu rodilla izquierda contra el suelo cuando realizas el corte vertical hacia abajo. Detente a un centímetro sobre el suelo y luego baja lo que queda. En este punto tu posición es la misma que cuando terminas \#2 Migi.

\section{Sacudiendo la sangre a un lado frontal $\rightarrow$}

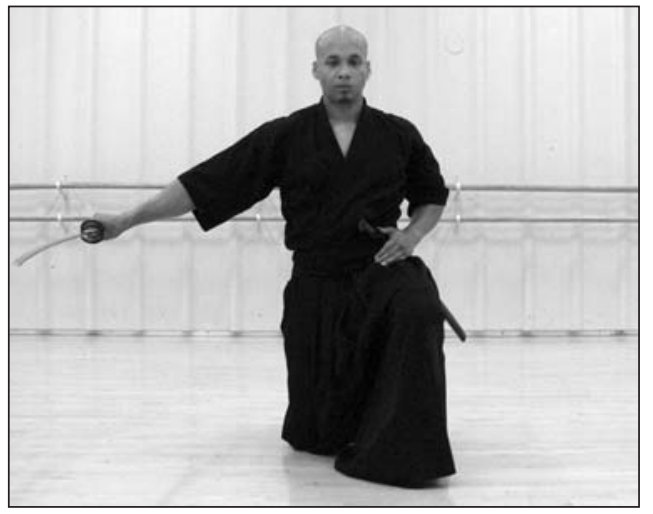

Esta es la primera vez que nos encontramos el movimiento Sacudiendo la Sangre a un Lado (yoko chiburi), que es el chiburi más común en la escuela. Suelta la empuñadura con la mano izquierda mientras mueves la espada muy ligeramente hacia delante con la derecha. La mano izquierda se mueve hacia la apertura de la funda, sujetando la funda en el cinturón en el lado izquierdo. Moviendo la hoja como un todo, sin dejar la punta atrás, sacude la espada directamente hacia el lado derecho para que se pare unos $20 \mathrm{~cm}$ a la derecha de la rodilla derecha. La punta señala directamente hacia delante y está ligeramente por debajo del nivel de la hoja en la guardia. La hoja está plana con el filo apuntando hacia fuera de tu cuerpo.

Normalmente, cuando ejecutamos chiburi olvidamos mantener las caderas vivas, y en ese momento todo nuestro peso está en nuestra rodilla bajada. Esto produce algunas inestabilidades y gruñidos de esfuerzo cuando nos levantamos. Lo siguiente que ocurre en esta kata nos enseña a no ser tan descuidados. 


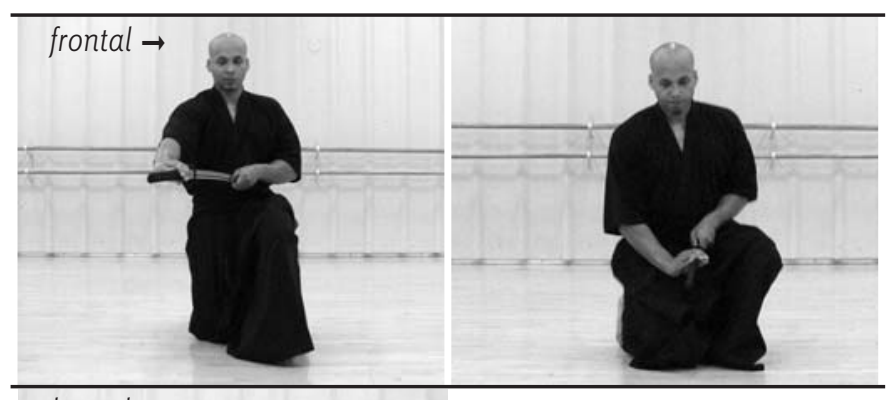

Envainando la Espada

$\# 1$

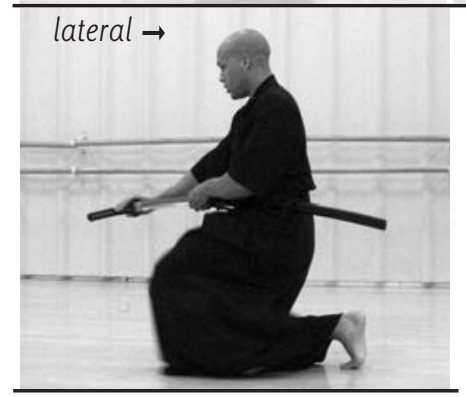

Desde esta posición, mueve el extremo libre de la funda al centro y lleva la parte trasera de la hoja por encima directamente para realizar el envainado. Desenvaina la espada y colócala en la funda como en Mae. Mientras deslizas la espada dentro de la funda, mantén una "vigilancia relajada" y retira el pie izquierdo hacia dentro y hacia el ángulo derecho de modo que el talón izquierdo esté cerca del hueso del tobillo. De nuevo, tenemos que utilizar la cadera para realizar este movimiento. No podemos llevar nuestro cuerpo hacia atrás hasta que no haya peso en el pie y luego retirarlo. Si somos atacados cuando hacemos eso, estaremos indefensos. En cualquier punto de ese movimiento de retirada del pie tenemos que ser capaces de levantarnos en una posición erguida. Para hacer esto, tenemos que retirar el pie con algo de peso sobre él, y utilizar la cadera para desplazar el pie. Ahora podemos responder si es necesario, cosa que efectivamente así es.

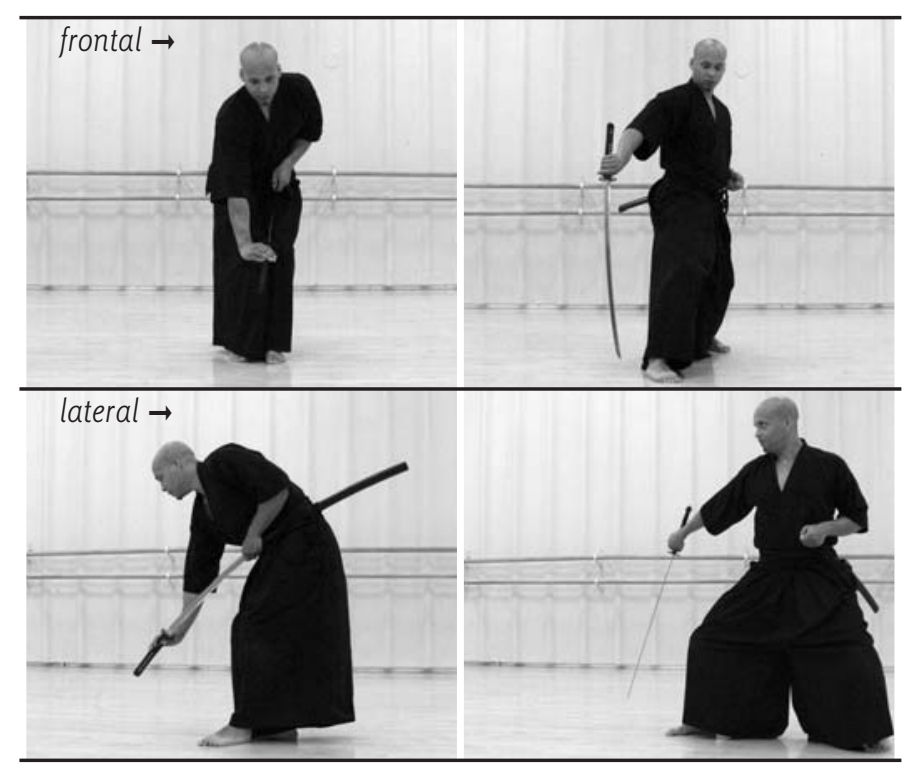

\section{Desenvainar y Cortar \#2}

(Guardia de la Espinilla)

Justo antes de colocarte para envainar la espada, el oponente se dirige a cortar con su espada hacia el lado exterior de tu rodilla derecha. Desenvaina la espada hasta que queden $2 \mathrm{~cm}$ en la funda mientras te levantas. Con una fuerte retirada de la funda, saca la punta y blándela en frente de tu pie derecho para parar aproximadamente a $20 \mathrm{~cm}$ delante y $10 \mathrm{~cm}$ a la derecha de los dedos de tus pies. Gira la parte trasera de la hoja hacia tu pierna mientras bloqueas la hoja del oponente, evitando de este modo que tu pierna sea dañada si la hoja es golpeada otra vez hacia tu espinilla. 
Corte final \#2

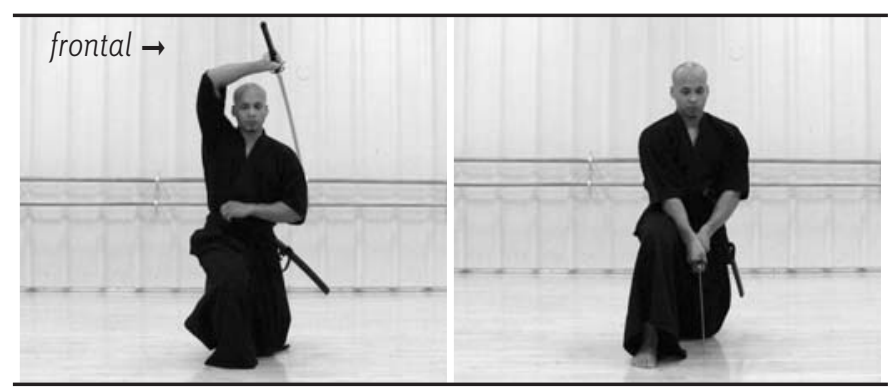

Cuando blandes la espada hacia abajo, el pie izquierdo es empujado en línea recta hacia atrás para adoptar una postura diestra. Asegúrate que es una postura fuerte y que las caderas están estables para que el bloqueo sea sólido. Las caderas están giradas normalmente en una posición medio lateral (hanmi) en este bloqueo, y si están flojas tu bloqueo no aguantará. La mejor manera de alcanzar esta posición es pensar en empujar el talón izquierdo hacia fuera desde tu centro, y girar los dedos del pie tan cerca como sea posible hacia el oponente sin perder la potencia en el brazo derecho.

Baja la rodilla izquierda hacia el ángulo derecho mientras conduces la espada alrededor del lado izquierdo de tu cuerpo, y levántala por encima de tu cabeza. Cambia el pie derecho hacia delante a la posición correcta mientras realizas un corte descendente en el cuerpo del oponente a medida que éste va al suelo. Es importante moverse bajo la espada con tus caderas en lugar de retirar la espada y quitar presión sobre el oponente. Al final del corte, las piernas tienen que estar con las rodillas en ángulo recto y la espalda recta. Todo esto se realiza mejor trabajando desde las caderas, llevándolas hacia abajo bajo la espada y hacia el oponente.

Para evitar dejar caer las caderas y levantarlas otra vez, también tienes que expandir las caderas hacia arriba (mantén la pierna izquierda extendida hacia abajo) cuando colocas la rodilla izquierda en el suelo. Aquí se refuerza la importancia de una postura erguida.

En este punto, termina la kata como se hace en Mae.

\section{Sacudiendo la Sangre \#2}

frontal $\rightarrow$

\section{Envainando la Espada \#2}

\section{frontal $\rightarrow$}

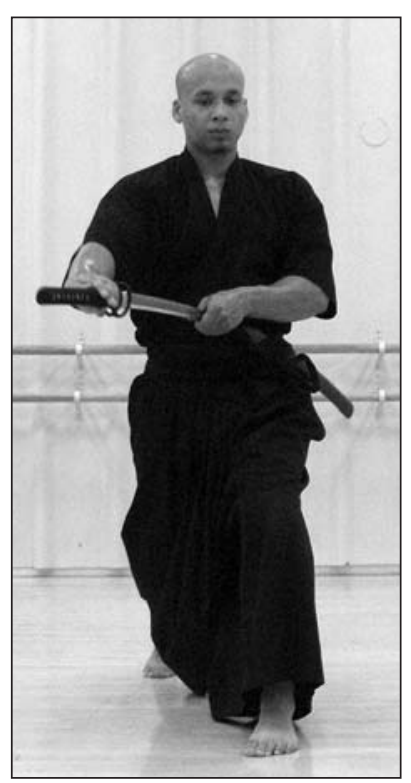

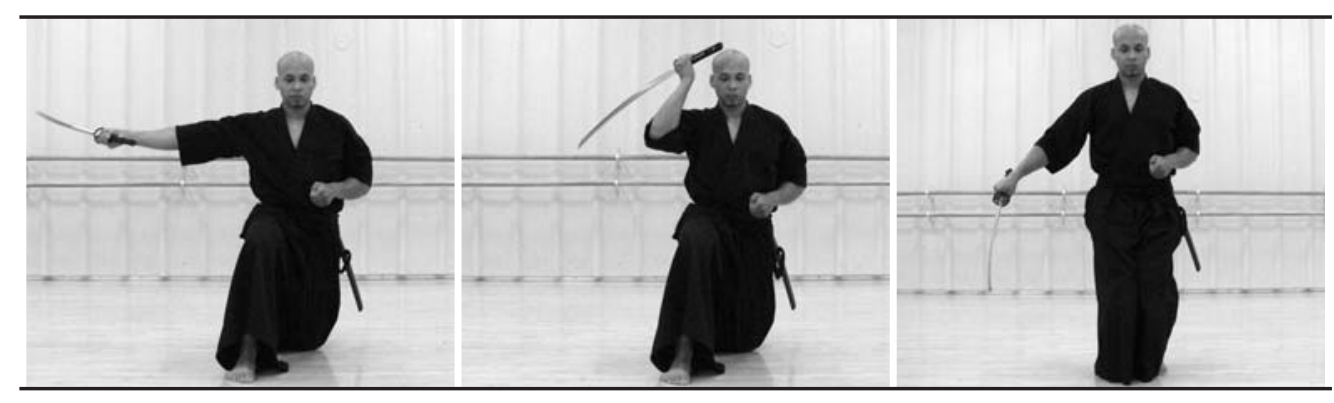

Lecciones aprendidas: Primero, mientras se realiza el corte horizontal inicial, se suele mencionar el pie atrasado. Aquí es donde se presenta el concepto de levantar la rodilla atrasada claramente del suelo en el corte inicial. Esto es para permitir el empuje directo hacia delante en todo el paso antes de realizar el corte vertical suavemente y sin vacilación. También proporciona una cadera mucho más fuerte y estable para el corte horizontal, y por eso debería ser puesto en práctica en las cuatro primeras katas. Por supuesto una vez que se intenta esto, aparece el problema de cómo deslizarse hacia delante para el corte vertical. Es entrenando cómo llevar el pie atrasado hacia el suelo mientras todavía se es capaz de deslizarse hacia delante en el corte donde el estudiante aprende más incluso sobre la cintura pélvica y cómo funciona. Ser capaz de hacer todo esto suavemente, sin balanceos hacia arriba y hacia abajo o inclinándose atrás y adelante es una habilidad compleja que tiene que ser entrenada sistemáticamente, como hemos hecho aquí.

El bloqueo después del segundo ataque es la introducción de una postura erguida donde necesitamos ser tan precisos con la posición de la cadera como con nuestras rodillas. Se retrocede el pie izquierdo y el talón se gira hacia fuera para conseguir una postura firme. Si se mueve el pie con negligencia, es probable que la cadera quede floja y el bloqueo fracasará. El retroceso hacia abajo con la rodilla izquierda para el corte final también se hace desde las caderas.

Todo este movimiento facilita la oportunidad para practicar el control de las caderas para que el cuerpo se conduzca suavemente, y los cortes y bloqueos sean precisos. 
El corte final hacia abajo es una gran prueba para el torso. Sin ningún tipo de inclinación hacia delante, el estudiante conducirá su hoja hacia el suelo. Una postura recta significa que la hoja se detiene a $2 \mathrm{~cm}$ del desastre.

La clave en esta kata es un equilibrio de potencia entre los pies en todo momento. No debemos balancear nuestro cuerpo de un pie a otro si hemos de estar preparados para movernos rápidamente en cualquier dirección. Con dos rodillas, una rodilla y un pie o dos pies en el suelo, debemos estar listos para movernos sin vacilación ni preparación.

Reflexión: En este punto, si estás entrenando durante este artículo, intenta hacer el primer desenvaine y corte de Mae. Haz el corte horizontal sin peso en la rodilla izquierda. Ahora, sin dejar caer tu peso sobre la rodilla para entrar hacia delante, haz el corte vertical con un impulso hacia delante de las caderas. Parecerá imposible de realizar, pero puede hacerse si mantienes presión en las caderas hacia delante y simplemente levantas el pie derecho del suelo. Recuerda moverte desde las caderas, no desde el pie izquierdo, o podrían suceder todo tipo de cosas no deseadas.

\section{ACLARACIÓN}

En las siguientes tres katas aprendemos cómo dejar caer nuestro peso sobre el corte y a manejar nuestras rodillas y tobillos para estar libres para movernos. Hasta ahora el cuerpo ha estado estable a través de las caderas porque hemos estado arrodillados en el suelo, pero ahora tenemos que levantarnos.

\section{RECIBIR \& DESVIAR}

En esta kata, el atacante se mueve hacia nosotros desde el lado izquierdo y lanza un corte hacia abajo dirigido a nuestra cabeza. Cuando comienza a cortar, desenvainamos la hoja horizontalmente hacia delante mientras damos un paso hacia delante con el pie izquierdo. Ahora nuestro atacante levanta la hoja y corta de nuevo hacia nuestra cabeza. Eleva la hoja y gira a la izquierda para bloquear el golpe. Para hacer esto, mueve el pie derecho por encima de modo que estés encarando al atacante.

Ahora, gira el pie izquierdo en el sitio y da un paso hacia él con el pie derecho mientras levantas la espada y cortas hacia abajo sobre el oponente con una fuerte caída de la cadera. Retira el pie izquierdo a lo largo de la línea de ataque original del oponente mientras mueves la empuñadura por encima al frente y a la izquierda, y coloca la punta sobre la rodilla derecha. Cambia el agarre de la mano derecha y luego deja que la punta se balancee abajo y arriba otra vez mientras mueves el reverso de la espada a la mano izquierda. Saca el reverso de la hoja y pon la punta en la apertura de la funda, luego recoloca la hoja, dejándola caer sobre la rodilla izquierda mientras regresa a la posición original. Ahora la mano derecha regresa a su posición inicial, por lo que cuando terminas el enfundado puedes cambiar al agarre normal con la mano derecha y luego levantarte y retroceder como en Mae.

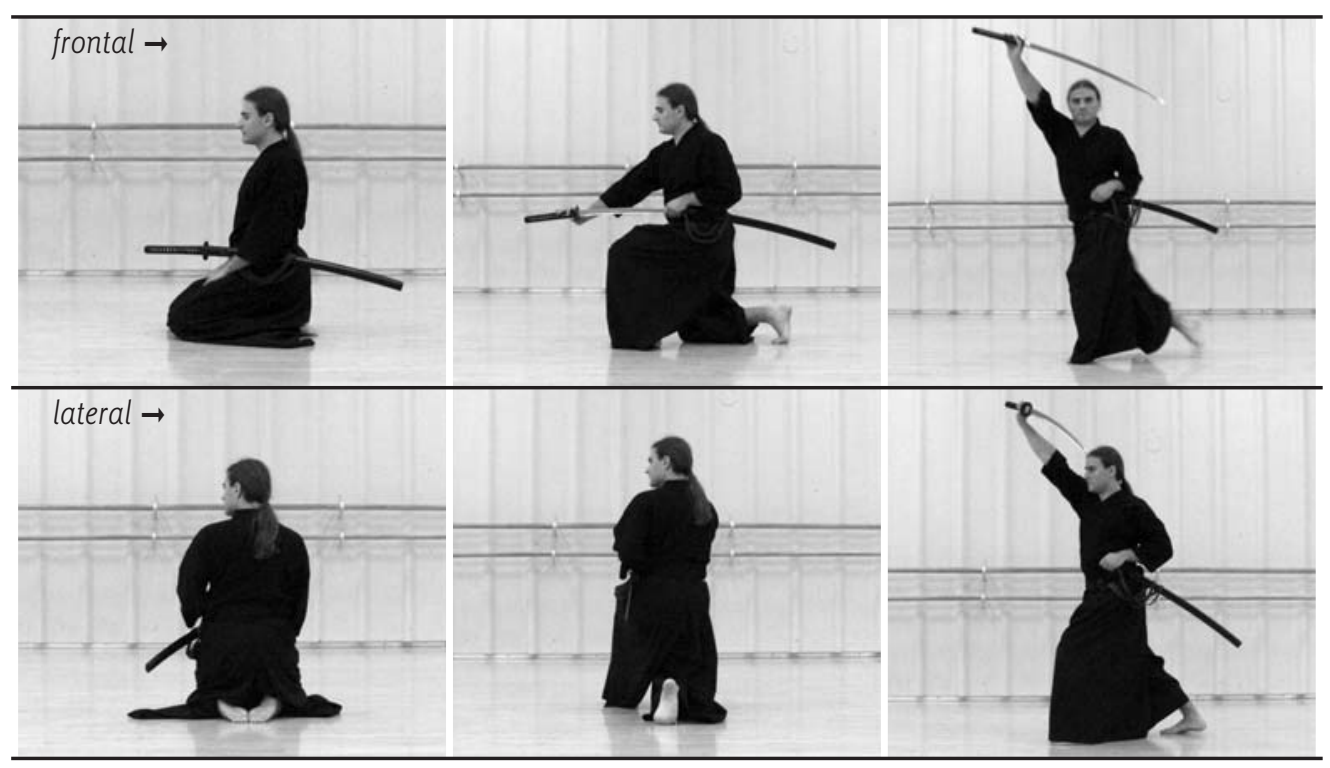

Desenvainar y Cortar

Revista de Artes Marciales Asiáticas $\diamond$ Volumen 4 Número 2 (74-95) - 2009 
Cuando observas que el oponente comienza a atacar, impúlsate hacia delante para evitar el corte levantándote sobre tu rodilla derecha y dando un paso hacia delante con el pie izquierdo. Al mismo tiempo, desenvaina la hoja horizontalmente hacia delante. Aquí la lección debería ser obvia, tienes que mover tus caderas fuera del camino del corte, en vez de agacharte. Si simplemente te balanceas hacia delante el oponente te cortará en la parte baja de tu espalda. Muévete hacia delante desde tus caderas y quita el pie izquierdo de la trayectoria; el oponente podrá estrellar la espada contra el suelo sin golpearte.

En un movimiento veloz, el oponente ahora levanta la espada rápidamente y vuelve a cortar hacia abajo. Para bloquear este corte, da un paso hacia delante con el pie derecho hasta una posición donde tu cuerpo esté alineado encarando al oponente, y levanta la hoja para llevar el corte sobre el área justo en frente de la guardia de tu espada, sostenida horizontalmente delante y sobre tu cabeza.

El pie izquierdo todavía está girado, para que hayas tenido una posición del pie derecho más firme para recibir el corte, o tu rodilla izquierda sufrirá. La posición del cuerpo tiene que aguantar un golpe con la máxima fuerza y transferir la potencia a través de tu centro y hacia abajo hacia tu pie derecho. Aquí se evalúan cuidadosamente las posiciones del brazo, cadera y pierna. Ahora se ven claramente las líneas de fuerza moviéndose desde la espada hasta el suelo, y cuando uno regresa a Mae, las líneas desde la punta de la hoja hasta el pie izquierdo también están un poco más claras.

\section{Corte final}

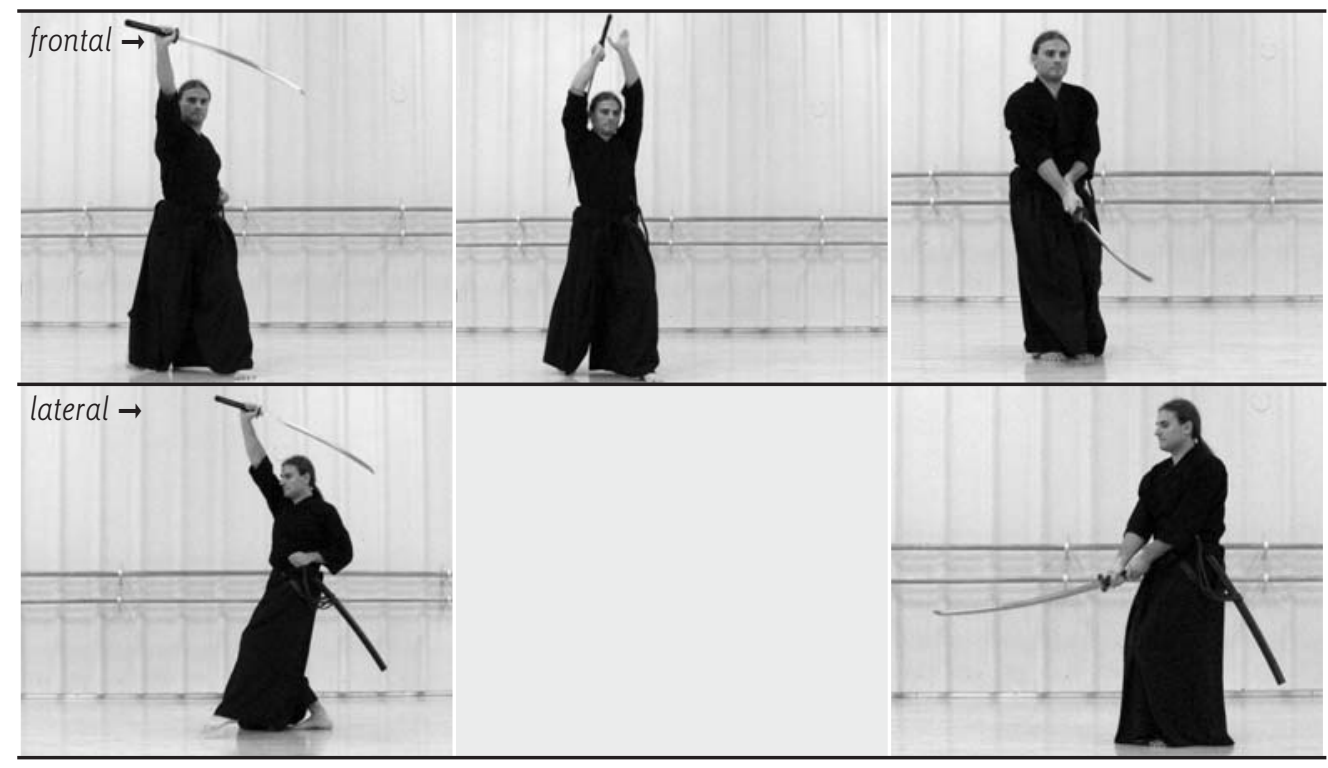

Después de una breve parada final en la posición de bloqueo, se gira la espada durante el movimiento de elevación (furi kaburi) y bajada, en un corte hacia abajo con una mano, hacia el cuello expuesto del oponente (kiri otoshi) mientras se inclina hacia delante para realizar un segundo corte. Este corte se realiza mientras se levanta el pie izquierdo, girado para encarar al oponente, y se baja otra vez. Mientras se realiza el corte y la mano izquierda se lleva a la empuñadura, se lleva el pie derecho al lado del izquierdo. El corte termina con la hoja en una posición horizontal, los pies juntos, las rodillas dobladas y las caderas bajadas.

Este es el primer corte que hemos realizado que depende casi por completo en dejar caer las caderas en vez de en una pierna atrasada reforzada. En vez de ser débil, como podría parecer a primera vista, el corte es sorprendentemente fuerte si podemos conectar la espada a través de nuestras axilas con las caderas. Aunque tenemos poco empuje de nuestros músculos de las piernas, tenemos la mayor cantidad posible de peso bajo la espada. Esto nos da una sensación real de dejar caer nuestro peso sobre un corte en vez de aplicar fuerza muscular sobre el mismo.

Instrucción progresiva inherente a la práctica... $\quad \diamond$ Kim Taylor 


\section{Limpiar la sangre}

El siguiente movimiento representa limpiar la sangre de la hoja. Manteniendo una "vigilancia relajada" (zanshin), se retira el pie izquierdo a nuestra parte trasera izquierda, hacia donde estas situándote actualmente para adoptar una posición llamada karuma. Las caderas están giradas fuera del ángulo recto y el talón izquierdo está apoyado sobre el suelo. El peso está distribuido por igual en ambos pies. Al mismo tiempo que se mueve el pie izquierdo, las manos se mueven hacia la izquierda para que la punta de la hoja se retire directamente para terminar de 2 a $5 \mathrm{~cm}$ sobre la rodilla derecha. La hoja está plana y el borde señala hacia fuera del cuerpo. En este momento, cogeríamos un trapo y limpiaríamos la hoja.

Esta posición de la cadera es parecida en sensaciones a la posición de bloqueo de la "defensa doble" (Yae gaki), reforzando esa lección. Cuando se coloca la hoja en la funda, las caderas están giradas en la posición inicial hacia delante, que será muy dolorosa o molesta si no hemos colocado nuestros pies en la posición correcta para comenzar.

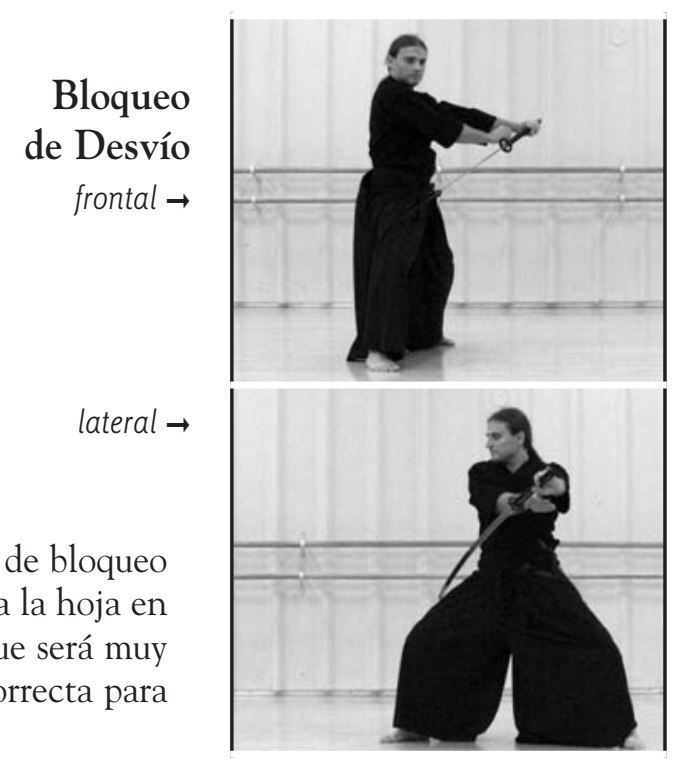

\section{Envainando la Espada}

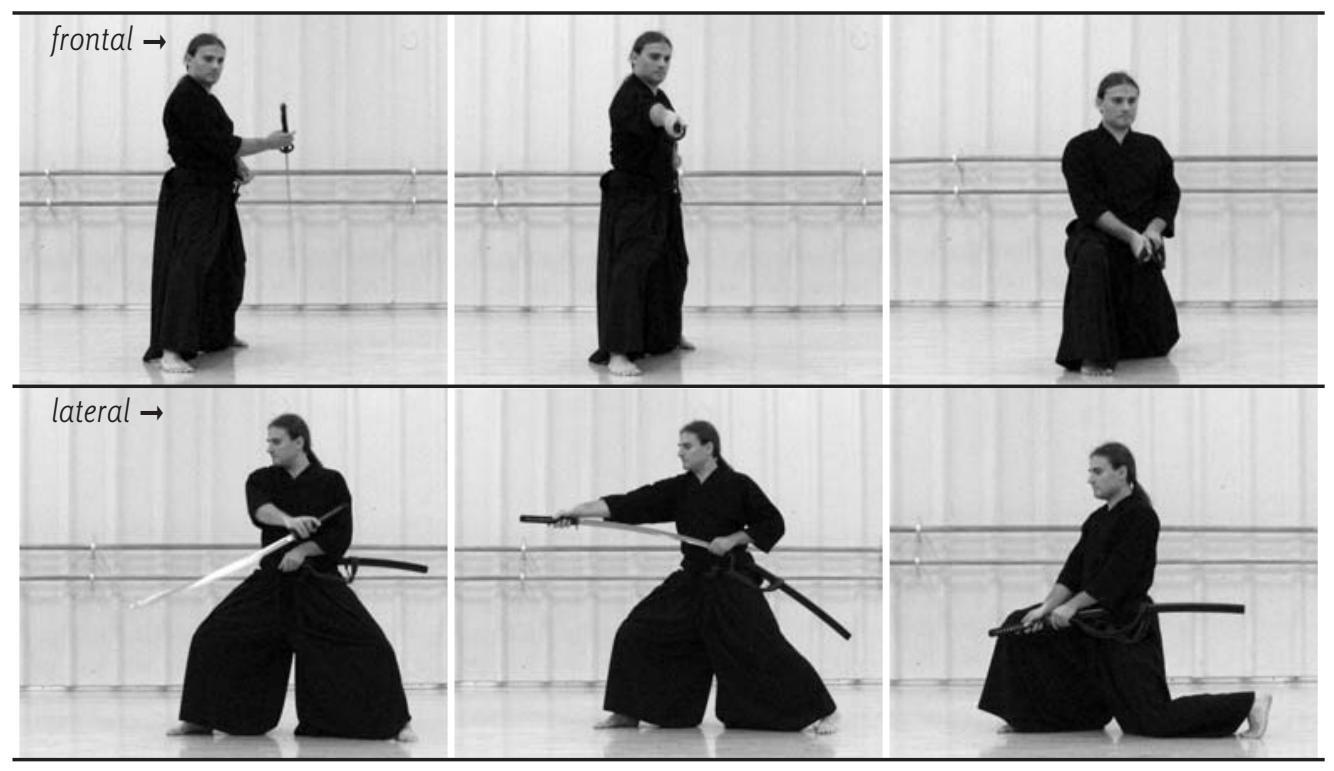

\section{Lecciones aprendidas:}

Hemos mencionado las lecciones arriba: el impulso de la cadera para evitar un golpe, las líneas de fuerza desde el pie atrasado hasta el área justo en frente de la guardia de tu espada (tsuba moto) en el bloqueo, y la fuerte caída del peso sobre el corte. Hemos aprendido a cortar con fuerza mientras permanecemos de pie sin quedarnos atrás sobre nuestra rodilla. La clave son las caderas. Las articulaciones por encima y por debajo de ellas tienen que estar controladas, tensándose o aflojándose como sea necesario para hacer el corte de la espada como deseemos.

\section{Reflexión:}

Ahora estamos expandiendo nuestra sensación de las caderas por todo nuestro cuerpo e incluso hacia la espada y el suelo. Ahora estamos preparados para regresar a \#1 Mae con una nueva apreciación de cómo "cortar desde las caderas" y cómo conseguir algo de verdadera potencia en la espada. La velocidad y el músculo son sustituidos por la potencia y el peso. 
Esta técnica es distinta a las descritas anteriormente. No es una respuesta al ataque de un enemigo sino que es un método para ayudar a alguien a cometer un suicidio. El kaeshaku es la persona designada para cortar el cuello de la persona que se ha sacado las entrañas a sí mismo. Esto es necesario, ya que la persona con este tipo de herida en el estómago puede sobrevivir durante largo tiempo con mucho dolor.

\section{Desenvainar y Cortar}
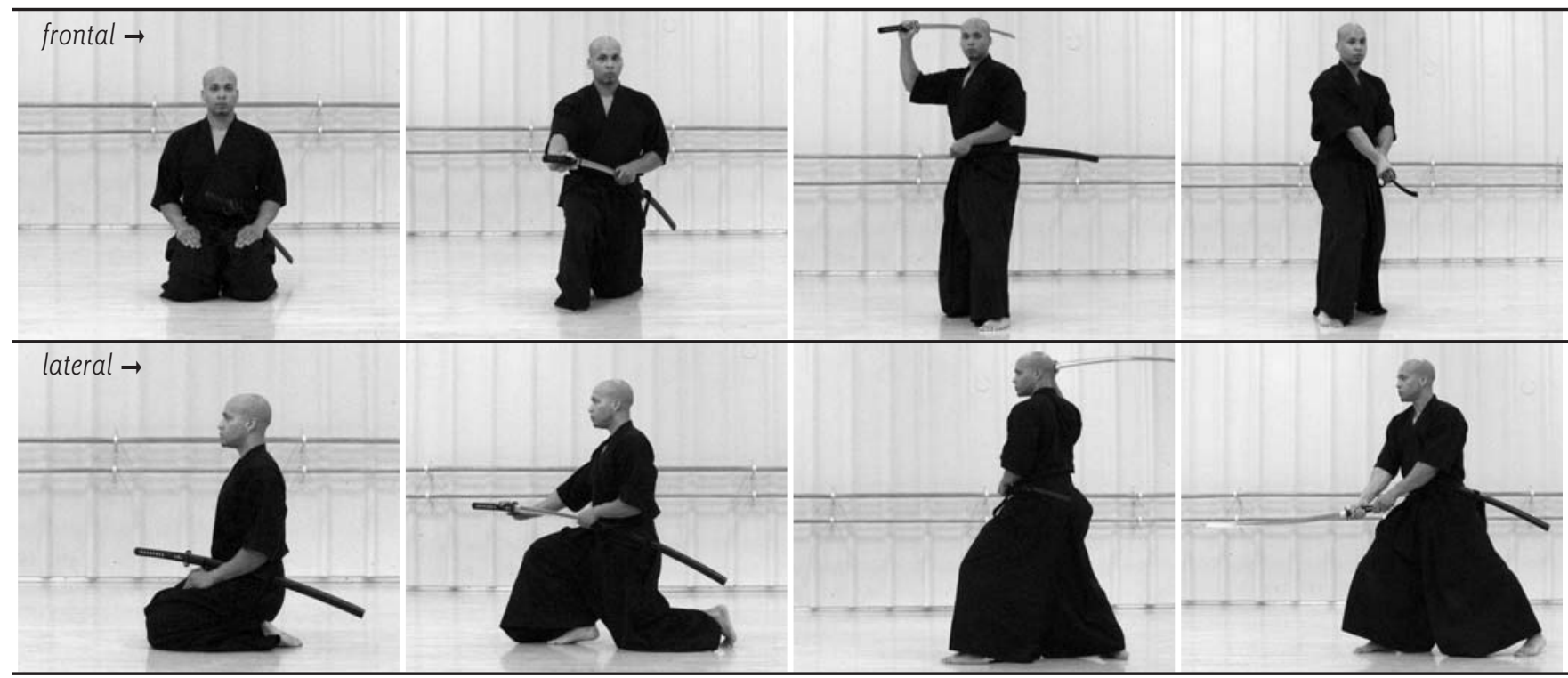

Desenvaina la espada horizontalmente detrás de la espalda de la persona que está realizando el suicidio mientras mueves el pie derecho ligeramente hacia delante. Levanta la punta de la espada sobre tu cabeza mientras retiras el pie derecho en una posición lateral izquierda (hanmi) con el codo derecho doblado a $90^{\circ}$, manteniendo el antebrazo vertical, y la hoja en el mismo ángulo que la funda. En el momento apropiado, corta hacia abajo el cuello con un agarre a una sola mano, acompañando con la mano izquierda para evitar que la punta corte a través de la piel la garganta. La posición es una postura lateral derecha

Sacudida de la Sangre y Envainado (hanmi o karuma). Lleva la hoja a la posición chiburi como en el anterior \#6 Uke Nagashi, invierte el agarre con la mano derecha, y luego envaina la espada con tranquilidad.

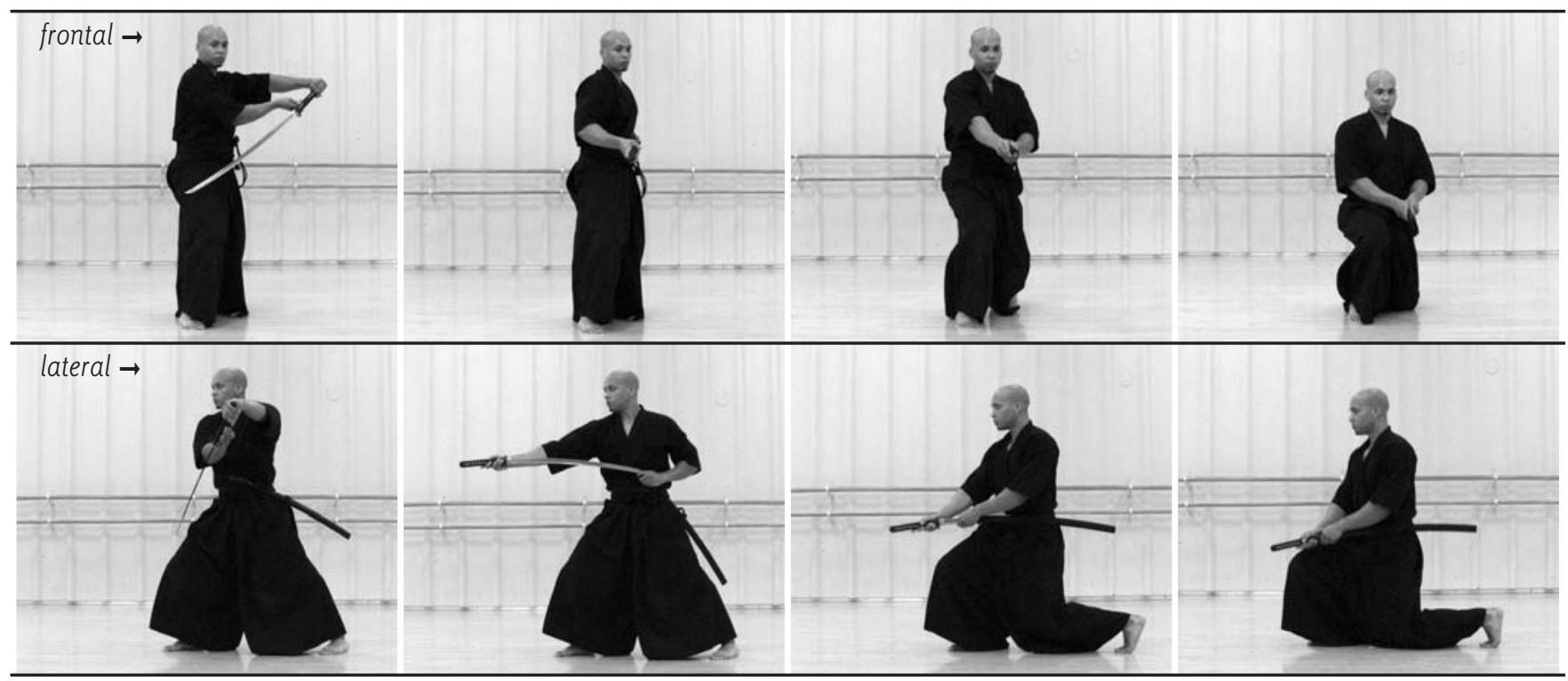


Lecciones aprendidas: Las lecciones físicas en esta kata no son tan importantes como las lecciones psicológicas, pero no profundizaré en esto ahora más que para hacer una pregunta sencilla. ¿Por qué se ha colocado esta kata aquí en la escuela? Ésta es la séptima (sí, la sichi o posición de la "muerte") kata en las primeras series de cosas que aprendes. De hecho, si consideras que las cuatro primeras katas son la misma (Mae desde cuatro direcciones diferentes), entonces ésta es la cuarta kata (shi o, de nuevo, "muerte"). ¿Por qué tan pronto? ¿Qué necesitamos aprender de quitar una vida a sangre fría, qué es tan importante de saber, tan pronto, en nuestra educación?

Por supuesto, físicamente seguimos aprendiendo. Los movimientos en esta kata no tienen un mal sentimiento hacia la persona que se está suicidando; no hay ningún enemigo presente, por lo que podemos movernos suavemente, con calma, y sin distraer a la otra persona. Esto significa que necesitamos un gran control de nuestras caderas y una tremenda fuerza en las piernas así como un toque muy delicado con la hoja. Estamos aprendiendo a distinguir las acciones enérgicas del corte de las acciones más suaves de mover la espada entre los cortes.

El corte tampoco es frecuente, comenzando mucho más bajo de lo que estamos acostumbrados, y parando tan repentinamente, siendo toda la potencia concentrada entre la espada y la parte anterior de la columna vertebral en el cuello. De hecho, el único lugar en toda la kata donde no se muestra ninguna fuerza es en esas pocas pulgadas de corte. Para realizar esto, tiene que haber una fuerte unión entre las caderas y los pies, y nada de tensión en los hombros.

\section{PARA UNA APERTURA EN DISTANCIA CORTA}

El oponente avanza hacia ti, intentando cortarte. Avanza y desenvaina con go ho nuki (como arrancar un rábano del suelo) hacia ti, la rodilla derecha arriba como en el desenvaine y corte de Mae. Cuando corta hacia tu cabeza, ponte de pie, levanta la hoja en un bloqueo de recepción y desvío (Uke Nagashi), y retira el pie derecho. Inmediatamente después de que su punta descienda más allá de tu nariz, da un paso hacia delante y corta desde su frente hasta su cuello. El pie izquierdo asciende cerca del derecho mientras cortas. Avanza una vez más con el pie derecho y el izquierdo después para cortar desde la frente hasta la ingle. Da un paso hacia atrás con el pie derecho y levanta la hoja a la posición de la postura superior (yodan gamae) para inspeccionar al oponente. Mueve a un lado la espada en un movimiento de corte mientras te flexionas sobre tu rodilla derecha. Sostén la empuñadura con el agarre inverso de la mano derecha, da la vuelta a la hoja y límpiala con tu mano izquierda, retirando la parte trasera de la hoja a lo largo de la palma izquierda. Enfunda la espada, levántate y luego retrocede a la posición inicial.

\section{Reflexión:}

Psicológicamente, nuestro Mae debería ser ahora más solemne y pesado, físicamente deberíamos estar moviendo la espada y nosotros mismos con gracia y control en las transiciones entre los cortes, mientras se aplica de forma instantánea una gran potencia desde el suelo hasta la punta cuando es necesario.

\section{\#8 - Tsuke komi}

\section{Desenvainar y Cortar}

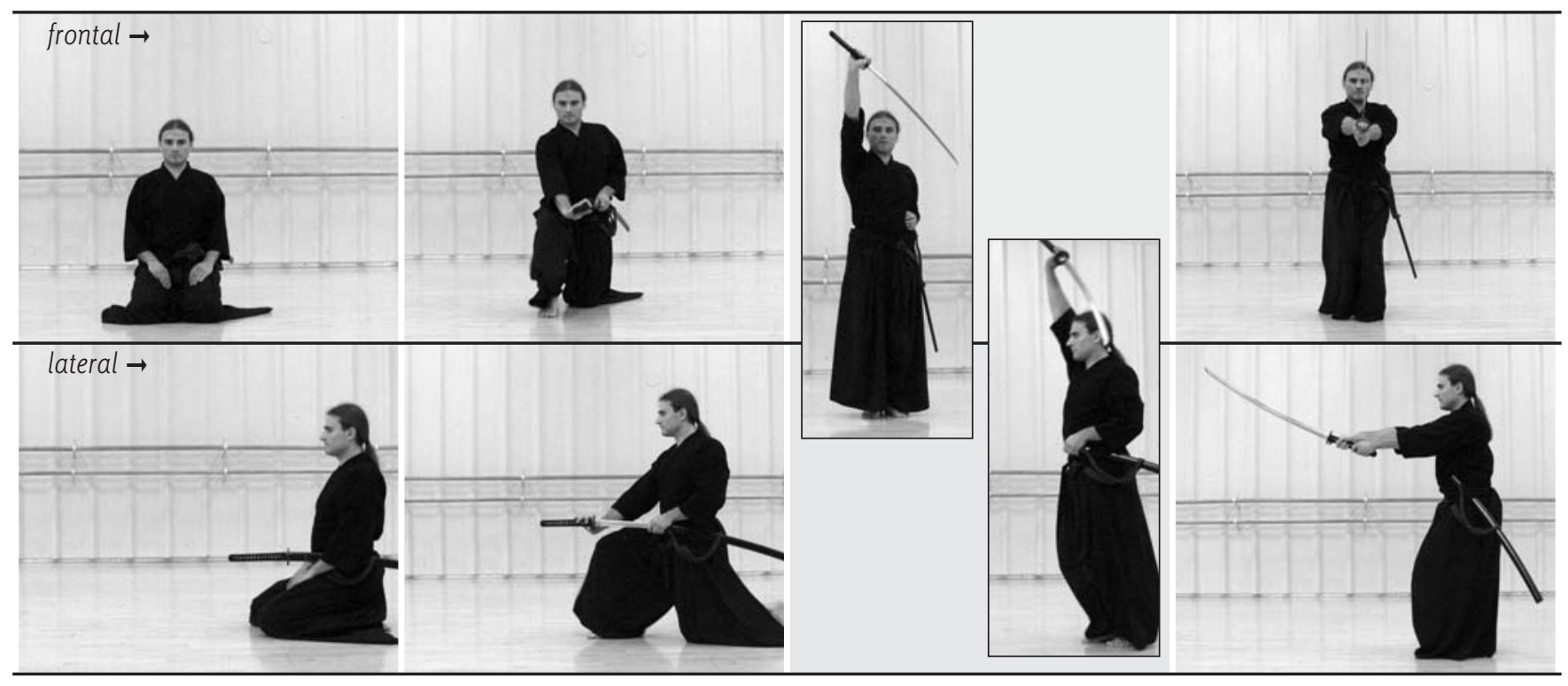

Revista de Artes Marciales Asiáticas $\diamond$ Volumen 4 Número 2 (74-95) - 2009 
Cuando realizas el primer movimiento para desenvainar la hoja tienes que provocar que tu oponente vacile y avance y corte con poca amplitud (hacia donde estás ahora). La técnica depende de esto y él no será tonto a menos que tengas la firme intención de continuar tu desenvaine en "Mae" y cortar transversalmente su estómago. Cuando se para en seco, justo fuera del alcance de tu desenvaine, y lanza un corte hacia tu cabeza, puedes ponerte de pie hacia atrás provocando que falle. Has estado preparado para realizar este movimiento corto y seco en una posición erguida por la kata que has entrenado hasta ahora en la serie. Ahora el movimiento instantáneo hacia atrás y arriba no es un problema.

Los dos cortes verticales se realizan con una sensación de dejar caer las caderas sobre la punta de la hoja, algo que ya hemos aprendido. Sin embargo, el movimiento entre ambos cortes es de extrema importancia. Esto tiene que realizarse con el propósito de presionar hacia delante desde las caderas y amenazar con la punta de la hoja al oponente. Sólo hemos hecho una marca en su frente con el primer corte que se hizo con una sola mano y muy rápido, por lo que tenemos que continuar haciéndole retroceder sobre sus talones. Si no nos movemos desde las caderas, o si vamos hacia atrás en el siguiente corte, se recuperará y escapará o atacará. El empuje hacia delante con la cadera desde nuestra posición con los pies juntos tiene que sentirse como el empuje hacia delante desde la postura correcta de sentados (seiza) en el desenvaine y corte como en \#1 Mae. No puede llegar desde los hombros.

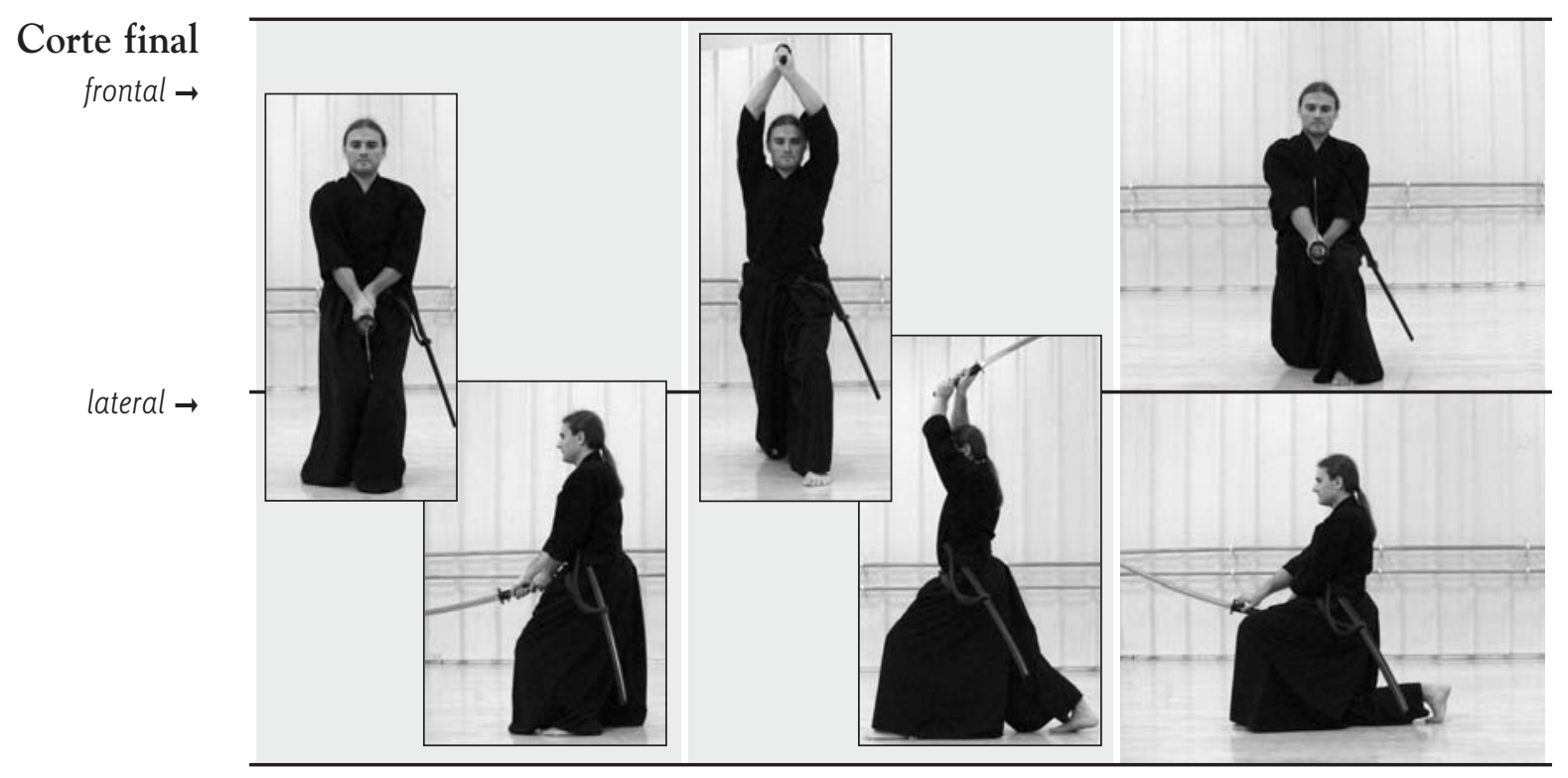

Da un paso hacia atrás con el pie izquierdo y levanta la espada bien alto, esperando a avanzar inmediatamente para cortar una vez más. Cuando el oponente se desploma, no tenemos necesidad de cortar, por lo que realizamos lentamente el movimiento de corte hacia abajo dejándolo caer (kiri otoshi) y nos flexionamos sobre la rodilla derecha, terminando sosteniendo la espada justo por encima de la horizontal con la empuñadura a la altura de la rodilla izquierda. Si hemos retrocedido adecuadamente y tenemos las caderas bajo control, no habrá ningún temblor alrededor de la parte superior del cuerpo y los

Sacudiendo la Sangre brazos. La espada se moverá con precisión y firmeza pero no con rigidez.
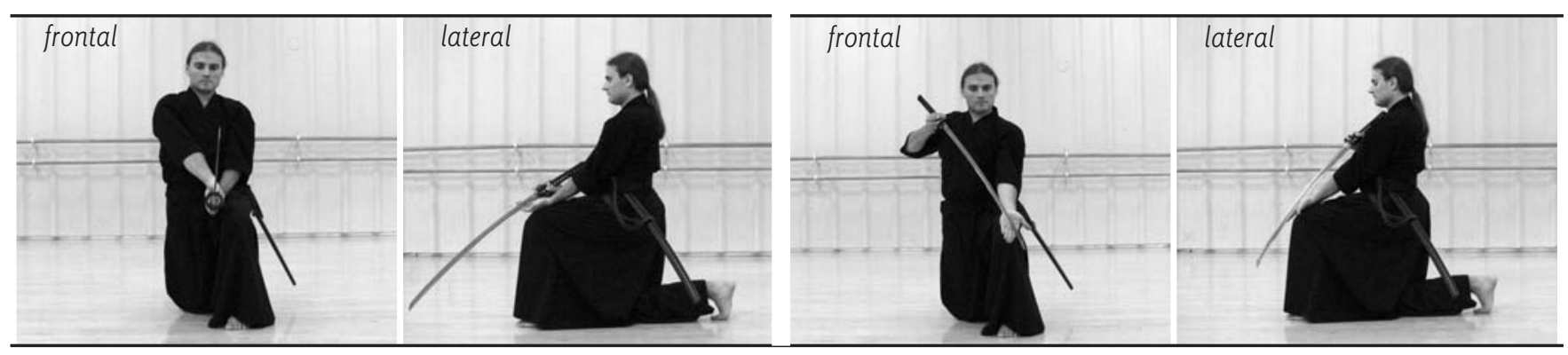
Se gira la mano derecha, la izquierda limpia la hoja, y se mete la espada en la funda una vez más, esta vez sin retroceder la pierna izquierda. Todo esto lleva bastante tiempo, y al final todo el peso del cuerpo está normalmente sobre la rodilla derecha por lo que permanecer de pie sin tambalearse o gruñir es imposible. Por supuesto, la lección es mantener el peso corporal entre los dos pies y mantener esa rodilla derecha flotando durante todo el movimiento. Una tarea muy difícil y que fortalecerá los músculos de la pierna. ¿Quizás haya algo que podamos hacer aquí con las caderas para ayudar?

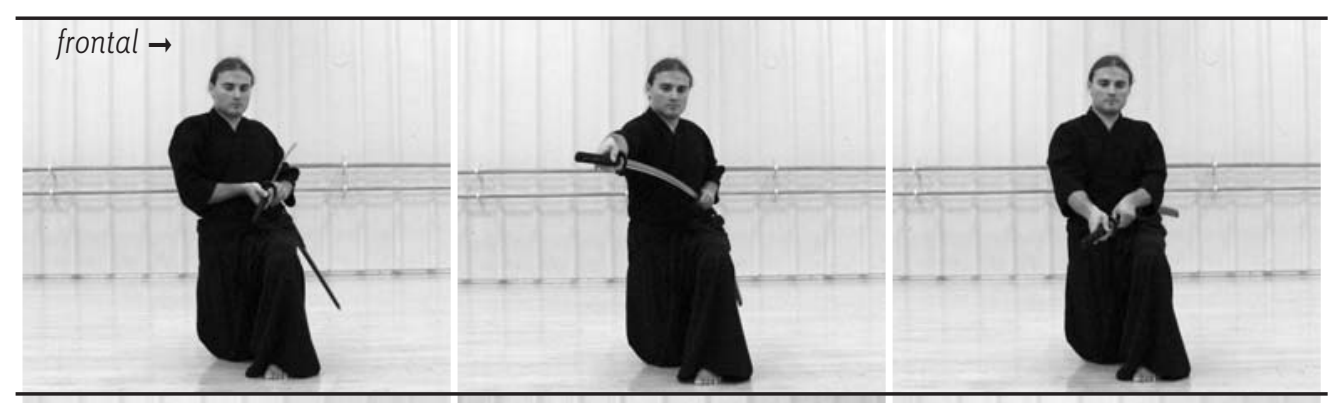

\section{Envainar}
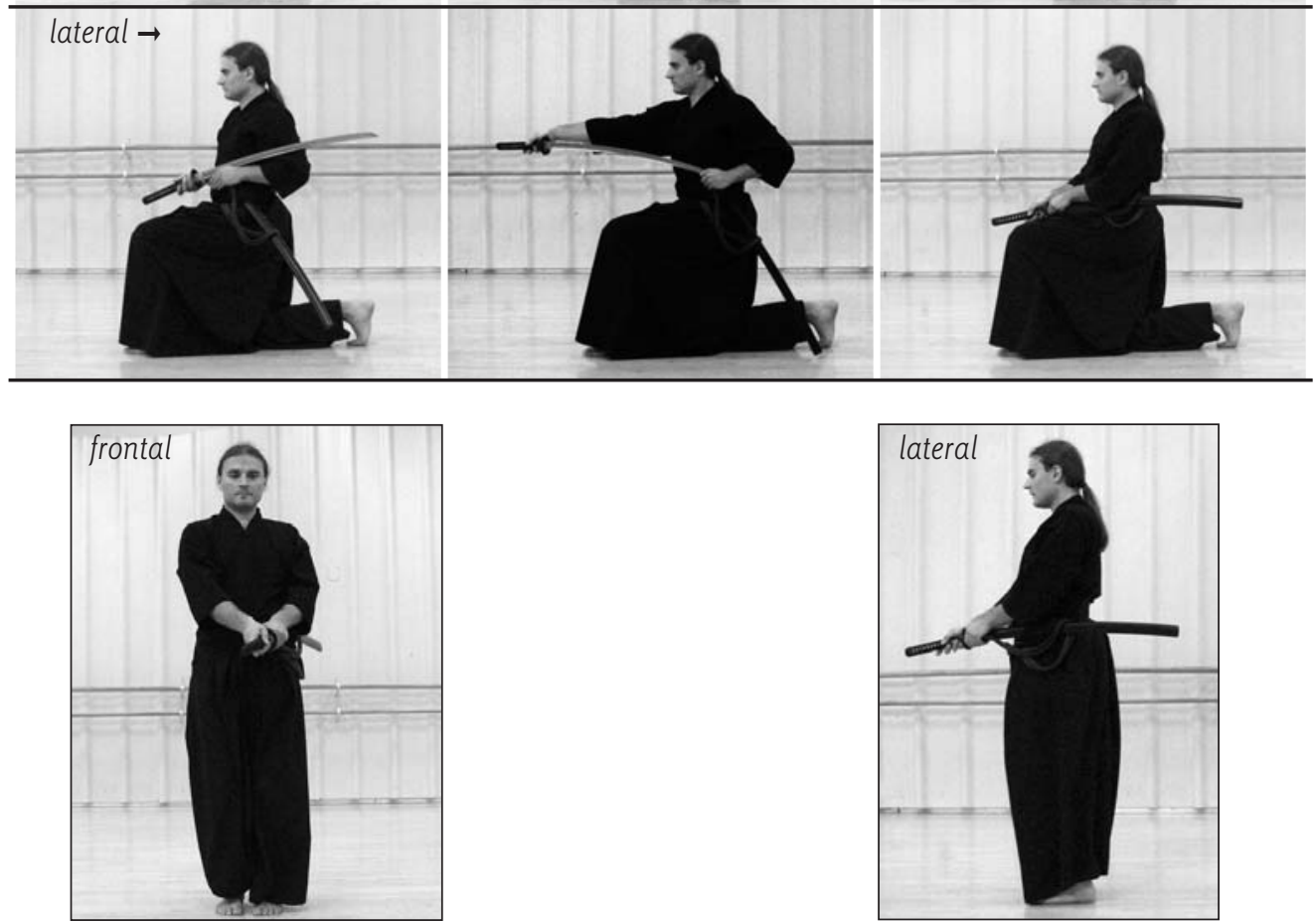

Lecciones aprendidas: De nuevo las hemos mencionado arriba, un potente y convincente impulso hacia delante, seguido de un movimiento bien definido sin peligro. Lo que es nuevo es la sensación de hacer retroceder al oponente sin descanso mientras ejecutamos los cortes verticales.

Reflexión: Tenemos que tener esta sensación de avance, haciendo retroceder al oponente hasta realizar \#1 Mae, especialmente en la sincronización entre el desenvaine y el corte, y el corte final. En un nivel básico también podemos aplicar este tipo de amenaza en el movimiento de desenvainar y cortar.

\section{ACLARACIÓN}

En las últimas tres katas cortamos desde varios ángulos y niveles (arriba y abajo) para completar nuestra esfera global de ataque. También regresamos al suelo y a los movimientos más básicos de espada en la kata final. 
Corte de desenvaine

Gira a la izquierda $90^{\circ}$ y siéntate en la postura formal (seiza). El oponente andará hacia ti desde el lado derecho y golpeará con un corte vertical hacia abajo (kiri otoshi). Empuña la hoja y mira al oponente. Desenvaina y gira sobre la rodilla izquierda mientras deslizas el pie derecho hacia él. Levanta la rodilla izquierda y corta a través de las muñecas del oponente de izquierda a derecha. Avanza utilizando un acortamiento y alargamiento de la postura (tsugi ashi) y corta hacia abajo desde la frente hasta la ingle. Realiza un gran chiburi mientras estás de pie, cambia los pies, y luego envaina la espada sin flexionarte sobre una rodilla.

Por supuesto este es nuestro viejo amigo \#1 Mae, realizado hacia un oponente a la derecha, pero ahora estando de pie en vez de estar en el suelo. Se aplican todas las lecciones anteriores, y parece que la única diferencia entre \#3 Defendiendo a la Izquierda y \#9 Sombra de la Luna (Hidari y Tsuke Kage) es el ángulo del corte horizontal.
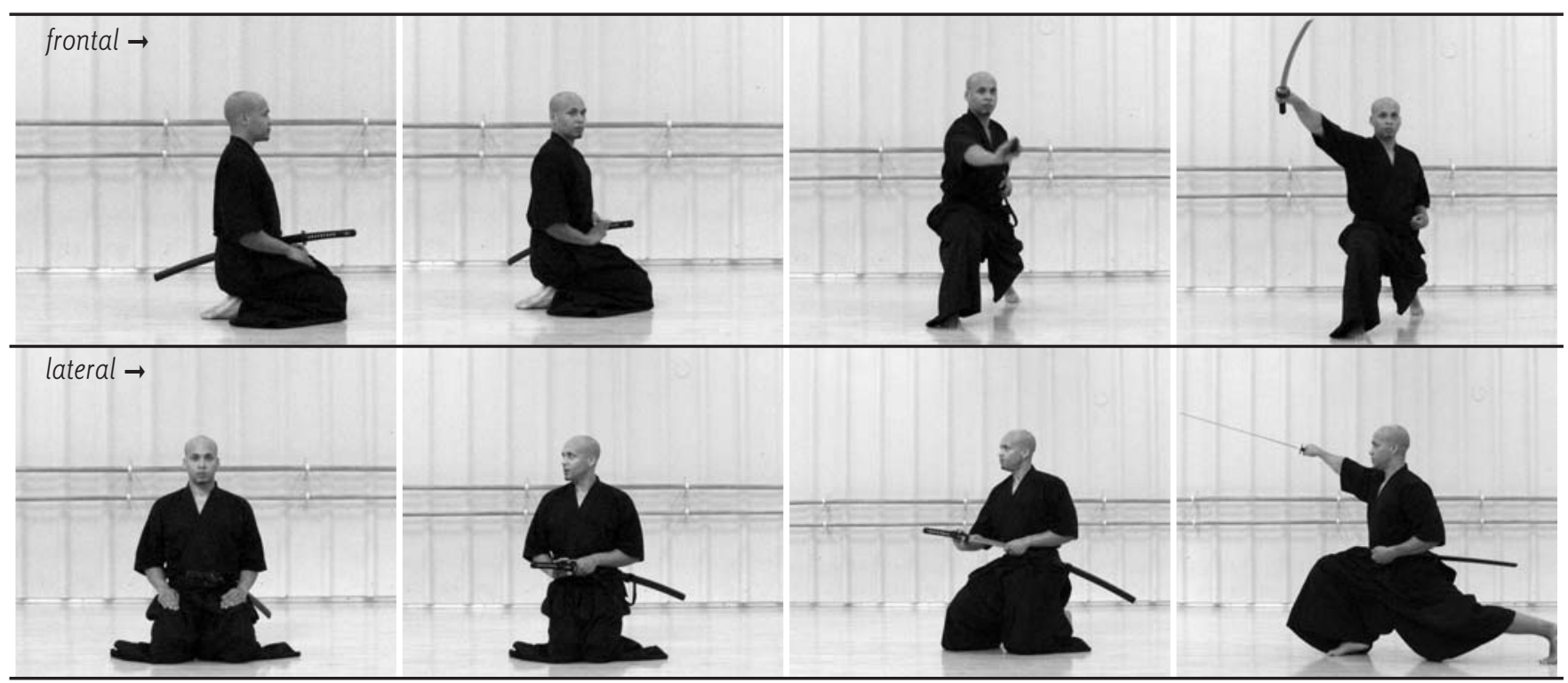

Hay, sin embargo, otra lección aquí, que está en el giro y elevación a una posición de pie muy baja en el corte de apertura. Girando y deslizando el pie derecho fuera hacia el oponente, nos movemos en realidad hacia él de tal forma que él no se da cuenta de que la distancia de combate ha cambiado, y podemos golpear sus muñecas antes de que él crea que podemos hacerlo. Otra lección es cómo nos levantamos en este corte. Si simplemente nos ponemos en pie, moveremos nuestra cabeza hacia el corte de ataque, por lo que tenemos, en vez de esto, que retirar el talón izquierdo hacia abajo contra el suelo mientras mantenemos las caderas a aproximadamente la misma altura que cuando estamos sentados formalmente (seiza). Esto requiere y permite una posición mucho más larga que, por cierto, nos permite poner nuestro pie derecho mucho más cerca del oponente.

Corte final frontal $\rightarrow$

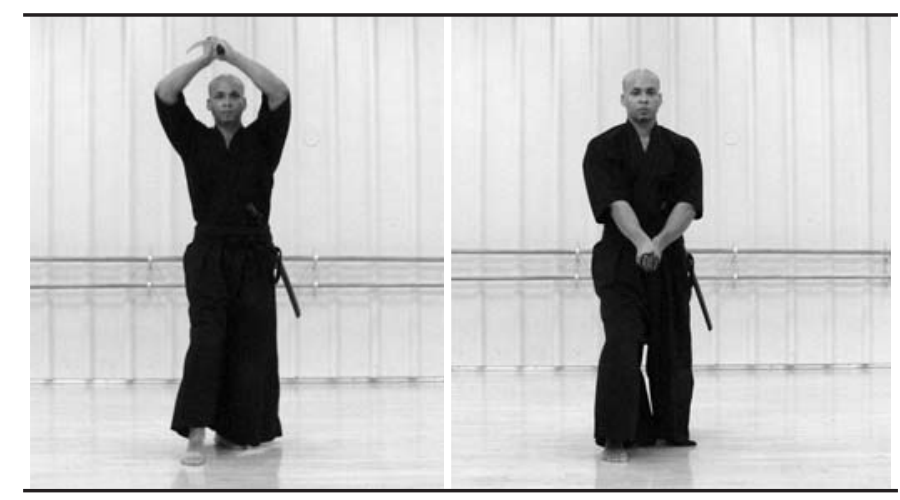


El chiburi y el envainado son similares a \#1 Mae, excepto en que no te flexionas sobre la rodilla puesto que permaneces de pie. Nos levantamos para responder a un oponente que está de pie, y la siguiente kata comienza desde de pie, por lo que permanecemos levantados para envainar. Esta es una lección en sí misma sobre el control de la cadera, ya que nuestro entrenamiento e instinto es descender cuando guardamos la espada.

\section{Sacudiendo la Sangre \& Envainado}

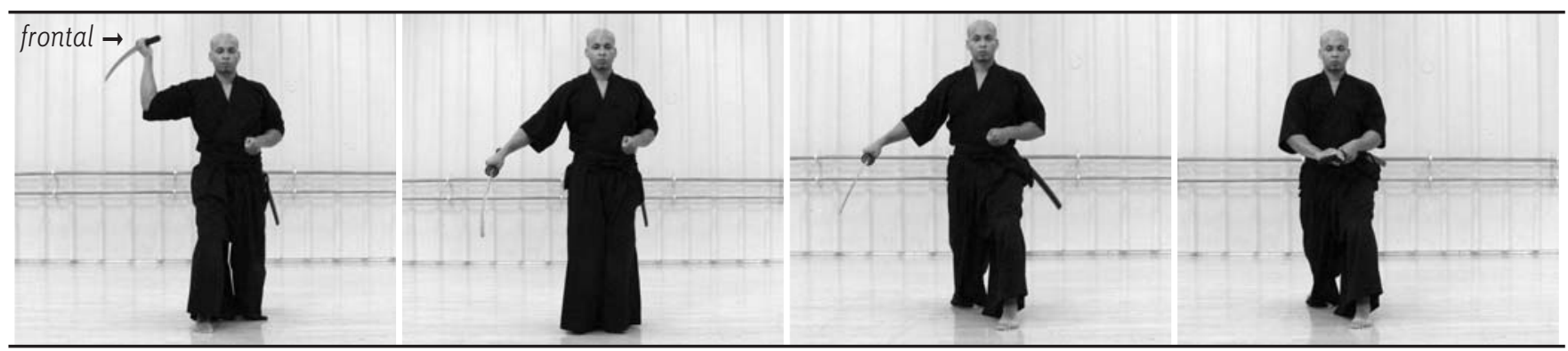

Lecciones aprendidas: Ahora podemos ejecutar \#1 Mae en cualquier dirección y a cualquier altura. También hemos aprendido el "acortamiento de distancia", moviéndonos hacia un oponente sin que se de cuenta de que estamos acortando el espacio. Esto es bastante diferente a la presión de empuje que aplicamos en la defensa de distancia corta de \#8 Tsuke Komi. Se realiza hacia la parte posterior, a diferencia del lado frontal de Tsuke Komi.

Reflexión: El control de la cadera y la potencia de esta kata, conducida por la pierna de atrás, tiene que aplicarse en \#1 Mae. La sensación de acortar la distancia también puede aplicarse al movimiento de desenvainar y cortar.

\section{PERSIGUIENDO EL VIENTO}

\#10 Oi kaze

Permanece de pie en la posición inicial de cara al frente. Tu oponente se escapa directamente de ti. Se retira, intentando conseguir espacio para desenvainar su espada.

Permanece de pie durante toda la kata. Agarra la espada cuando desciendes tus caderas y luego empuja la guardia para comenzar a desenvainar. Comenzando con el pie derecho, da dos pasos normales, luego cinco pasos de cortos a largos mientras desenvainas la espada, terminando con un desenvaine y corte horizontal de un lado a otro de los hombros del oponente. Da un paso hacia delante deslizando los pies (tsugi ashi); el pie izquierdo se acerca pero no supera al derecho cuando levantas la espada y luego cortas hacia abajo con el pie derecho adelantado. Realiza un gran chiburi y enfunda mientras permaneces de pie, y regresa a la posición de comienzo.

Sí, como sospechabas, esto es \#1 Mae mientras corres. Para comenzar, flexiona las rodillas mientras bajas las caderas y agarras la empuñadura, inclínate hacia delante hasta que te desequilibres sobre los dedos del pie. Ahora da dos pasos largos para recuperar tu equilibrio y para acortar la distancia entre tú y tu oponente. Él no tiene el espacio para desenvainar, por lo que tiene que comenzar a retroceder, y cuando lo hace tú le persigues. Mantén la distancia, cercana pero permitiendo que se amplíe cuando enderezas tu cuerpo, dirigiendo tus caderas hacia delante mientras desenvainas. Justo cuando la espada sale de la funda (saya banari), desenvaina y corta al oponente de hombro a hombro.

\section{Persiguiendo el Viento, Corte Desenvainando}

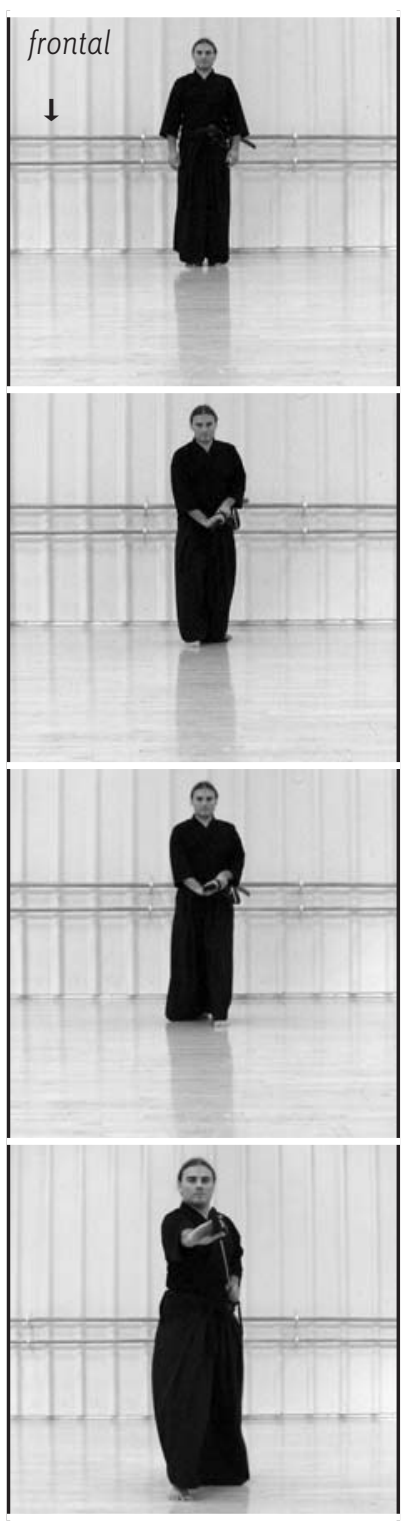

Revista de Artes Marciales Asiáticas $\diamond$ Volumen 4 Número 2 (74-95) - 2009 
Lleva el pie izquierdo hacia la derecha mientras levantas la espada. Da un paso hacia delante con el pie derecho y realiza un corte (kiri otoshi), finalizando con la hoja horizontal.

\section{Corte final frontal $\rightarrow$}

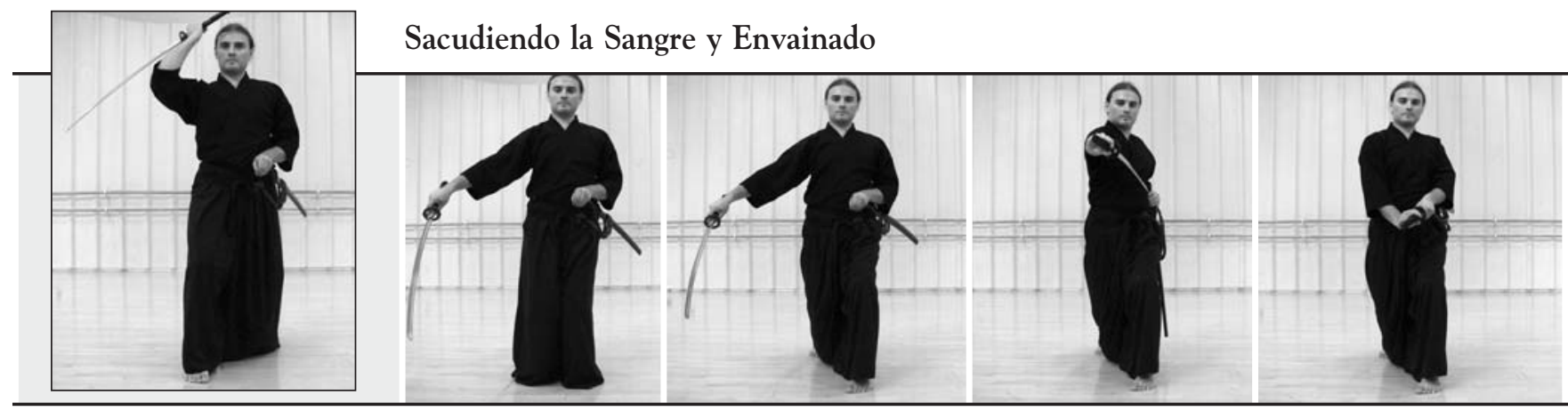

Mantén las caderas a la misma altura durante toda la kata. Muévete bajo la espada y mantén el movimiento hacia delante mientras ejecutas el corte final. Es importante mantener el impulso hacia delante con las caderas para asegurarse de que el oponente permanece sobre sus talones y retrocediendo.

Los movimientos de sacudida de sangre y envainado son como en \#9 Sombra de Luna
Lecciones aprendidas: La importancia de hacer una "carrera samurái” con los pies cercanos al suelo, pasos cortos y caderas bajas se hace ver en esta kata, ya que en cualquier momento podrías tener que parar y cortar, o incluso cambiar de dirección. La idea de una "plataforma estable del arma" ayuda en esta sensación. Imagina intentar alcanzar a alguien con un cañón muy potente que está sobre un bote pequeño; no se podrá realizar a gran distancia porque la plataforma está moviéndose en todas direcciones. Esta es la razón por la que se inventaron los acorazados, para proporcionar una plataforma que fuera suficientemente estable para que las armas alcanzaran un objetivo alejado varias millas. Se necesita lo mismo para la espada. Uno no puede golpear a un objetivo si las caderas están saltando arriba y abajo o yendo de un lado para otro. Mantenlas suaves y controladas.

Reflexión: Por supuesto, la misma idea de una cadera estable se traslada a \#1 Mae. Aunque puede no ser inmediatamente aparente que estás saltando arriba y abajo cuando estás sobre tus rodillas, después de intentar correr y tener las rodillas y tobillos flexionados debería ser más fácil sentir esa elasticidad en nuestra kata de base.

\section{DESENVAINAR Y CORTAR}

Una vez más, siéntate formalmente (seiza) de cara al frente. Tu oponente te está encarando como en \#1 Mae. Ataca directa y rápidamente. Cuando comienza a desenvainar, desenvainas desde la posición de sentado, levantas la hoja sobre tu cabeza mientras elevas tus caderas y luego cortas hacia abajo, doblando las rodillas para conseguir potencia. Realiza un pequeño chiburi lateral, envainado, y desciende las caderas otra vez. Cierra las rodillas, regresa a la posición formal inicial, y vuelve a poner las manos sobre el regazo. 


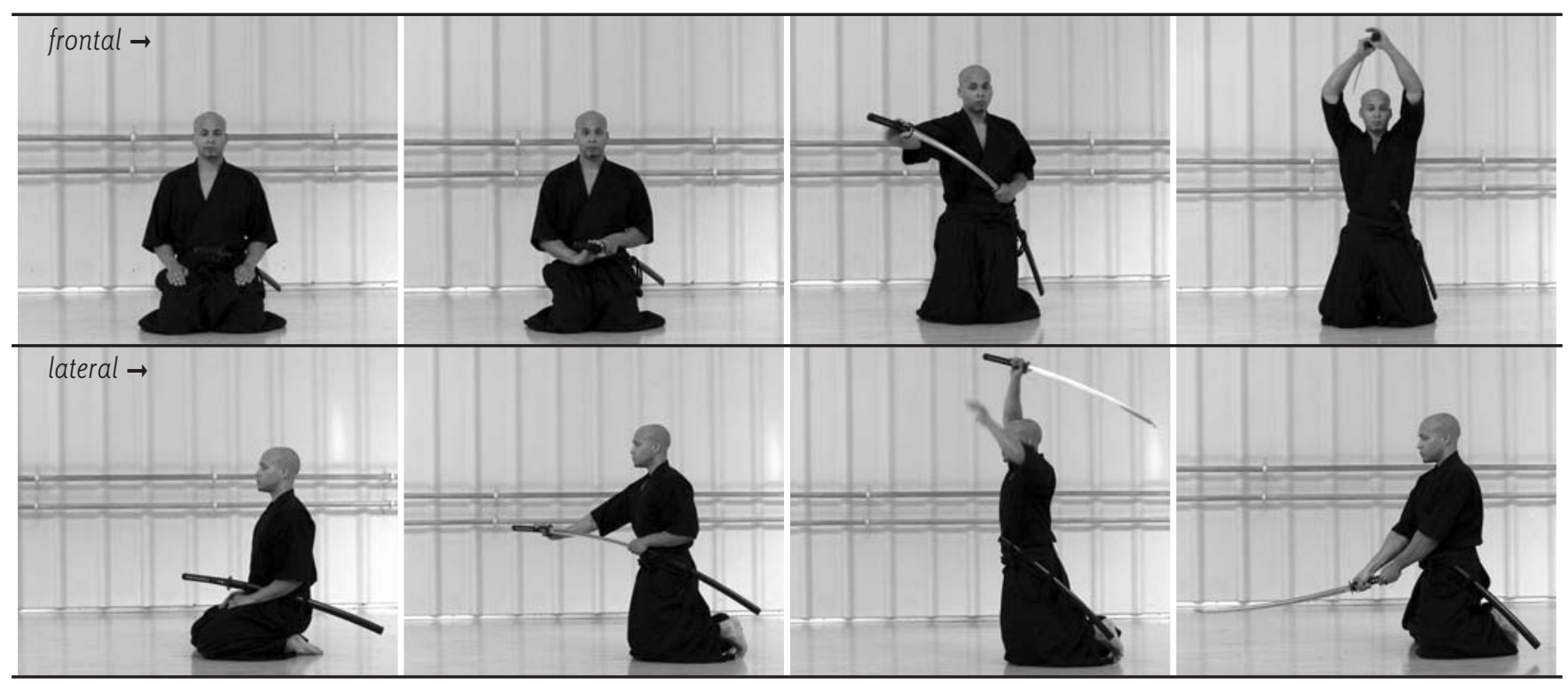

Lecciones aprendidas: Aquí tenemos la comprobación final de lo que hemos aprendido sobre las caderas. El desenvaine se realiza con un impulso hacia delante cuando nos ponemos de rodillas, por lo que nos deslizamos hacia delante aproximadamente $15 \mathrm{~cm}$ y luego cortamos mientras dejamos caer las caderas hacia abajo con la rodilla flexionada. Las caderas débiles y los hombros rígidos provocarán que nos cortemos nosotros mismos en vez de cortar al oponente.

\section{Sacudiendo la Sangre y Envainado}

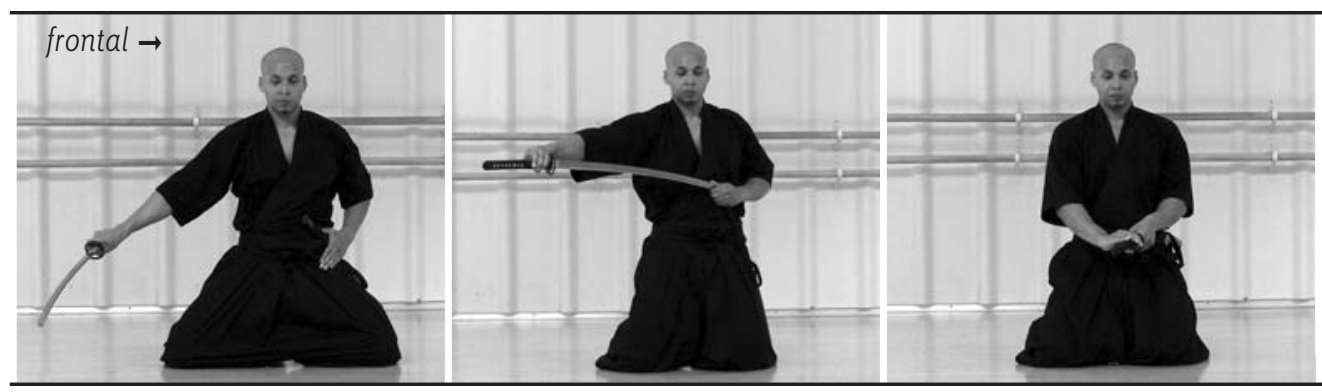

Al final de esta progresión de katas el estudiante ha aprendido los fundamentos del trabajo de espada, y más específicamente ha aprendido cómo utilizar las caderas de una forma eficiente y poderosa. Esto proporcionará una potente base para una posterior instrucción en otros niveles y ejercicios.

\section{Conclusiones}

Este artículo ha presentado un estudio de cómo se enseña el control de la postura, de la cadera, y la transferencia de potencia desde el suelo hasta la punta de la espada, a través de una progresión de katas. Las lecciones implícitas que se aprenden estudiando la serie en orden han sido examinadas parcialmente con la esperanza de que los estudiantes que las trabajen de este modo observarán su propia práctica y quizá tengan una comprensión parecida. Espero que este examen de la Omori-ryu de la Muso Jikiden Eishin-ryu haya proporcionado al lector alguna idea sobre cómo una progresión de ejercicios simples puede utilizarse para enseñar y aprender los fundamentos, y profundizar en esa práctica a través de varios ejercicios adicionales que destacan diferentes aspectos de las técnicas.

\section{Reflexión:}

Tener las caderas fuertes y los hombros relajados son, como siempre, la clave, y por supuesto esto es lo que llevamos de vuelta a \#1 Mae de esta kata final que es la esencia del iaido, un desenvaine directo hacia un corte final.

\section{Agradecimiento}

Me gustaría dar las gracias a Dennos Nikitenko y a Nathan Bain por la demostración de las técnicas.

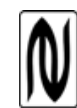

